Revue

d'ethnoécologie

\section{Revue d'ethnoécologie}

12 | 2017

La Poule. Pratiques d'élevage et histoire culturelle

\title{
Des cocottes en papier
}

La Poule dans la bande dessinée

"Paper hens". Hen in comics (1885-2015)

\section{Danièle Alexandre-Bidon}

\section{(2) OpenEdition}

\section{Journals}

Édition électronique

URL : http://journals.openedition.org/ethnoecologie/3307

DOI : 10.4000/ethnoecologie.3307

ISSN : 2267-2419

Éditeur

Laboratoire Eco-anthropologie et Ethnobiologie

Référence électronique

Danièle Alexandre-Bidon, « Des cocottes en papier », Revue d'ethnoécologie [En ligne], 12 | 2017, mis en ligne le 18 décembre 2017, consulté le 21 décembre 2020. URL : http://journals.openedition.org/ ethnoecologie/3307 ; DOI : https://doi.org/10.4000/ethnoecologie.3307

Ce document a été généré automatiquement le 21 décembre 2020.

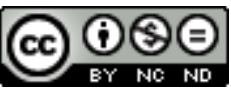

Revue d'ethnoécologie est mis à disposition selon les termes de la licence Creative Commons Attribution - Pas d'Utilisation Commerciale - Pas de Modification 4.0 International. 


\title{
Des cocottes en papier
}

\author{
La Poule dans la bande dessinée \\ "Paper hens". Hen in comics (1885-2015)
}

Danièle Alexandre-Bidon

« Attendu que la poule est un animal anodin et stupide, au point que nul n'est encore parvenu à le

dresser, pas même un cirque chinois ; que son voisinage comporte beaucoup de silence, quelques tendres gloussements et des caquètements qui vont du joyeux (ponte d'un œuf) au serein (dégustation d'un ver de terre) en passant par

l'affolé (vue d'un renard) [...] ; que la cour ne jugera pas que le bateau importune le marin, la farine le boulanger, le violon le chef d'orchestre, et la poule un habitant du lieu-dit La Rochette, village de Salledes (402 âmes) dans le département du Puy-de-Dôme'.»

\section{Éthologie de la poule... et de l'homme}

\section{La poule : bête...}

\section{La basse-cour et ses nuisances}

1 Depuis le XIX ${ }^{e}$ siècle, la littérature de jeunesse est peuplée de gallinacés ${ }^{2}$, et la BD dresse le portrait d'une cohabitation millénaire qui ne va pas sans tensions. Les nuisances de la basse-cour, surtout le cocorico matutinal, constituent une source d'inspiration inépuisable pour les humoristes ${ }^{3}$, ce dont font déjà état, sur le même ton plaisant que les juristes français, les premiers journaux de BD. Dans les années 1880, le magazine Ally Sloper's Half Holiday narre ainsi l'histoire d'un baron indisposé par le cri du coq au lever du 
jour et portant plainte - avant de découvrir qu'il s'agissait d'un volatile issu de son propre poulailler ${ }^{4}$.

De fait, quelle que soit l'époque, dans la BD - produite en ville et pour la bourgeoisie -, les gallinacés $^{2}$ n'ont pas droit de cité. Se réveiller au chant du coq est perçu comme " original $»^{5}$, dans les années 1940, ou «hippie», dans les années $1970^{6}$. Au début des années 1980, le coq, dont le comportement matinal est qualifié de ridicule, s'entend dire «Tu es fou de crier comme cela »?. En 1985, le Journal de Mickey peut encore donner aux jeunes lecteurs des conseils pour avoir « un coq en ville ». Mais, en 2003, un enfant qui en adopte un comme réveille-matin s'attire la colère de son père qui s'écrie : «[...] y'en a marre de ce réveil. C'est Paris, ici, pas la campagne! $»^{9}$. Son irrépressible besoin de réveiller les humains au petit jour fait du coq la victime toute désignée de voisins qui rivalisent d'idées pour le faire taire, allant jusqu'à lui scotcher le bec pour pouvoir dormir en paix ${ }^{10}$.

La ferveur avec laquelle le coq annonce le lever du jour trouve néanmoins ses chantres, et la scène donne lieu à quantité de dessins vernaculaires ou exotiques ${ }^{11}$, réalistes ou comiques $^{12}$. Dans la BD, le chant du coq est un moyen classique de signaler le passage du temps, le début ou la fin d'un épisode ${ }^{13}$, ou encore le déclenchement d'un événement historique, voire miraculeux. Il en est ainsi de la naissance de Jeanne d'Arc racontée aux enfants par les éditions catholiques. La nuit du 6 janvier 1412, jour de l'Épiphanie : «[...] voici que les coqs se mettent à chanter, comme s'ils avaient vu poindre le jour ». Pour son baptême, «Les cloches de Domrémy sonnent joyeusement, célébrant l'entrée de la petite dans la grande famille des enfants de Dieu, comme les coqs avaient célébré l'arrivée sur la terre de France de celle qui allait tant aimer son pays et se dévouer pour lui. $»^{14}$.

Plus dommageable encore que les nuisances sonores du chant du coq au petit jour, la poule est vagabonde. Elle passe son temps à égarer ses œufs - exprès, car les poules cherchent d'instinct un endroit isolé et tranquille pour les déposer - ou à les pondre dans des endroits improbables. Dans les années 1930, il faut à Betty Boop et à son scénariste, habitants d'un lotissement en open area, rivaliser d'imagination pour empêcher les poules d'un voisin de venir dévaster leur gazon (Betty Boop 1975). Dans les années 1950, une publicité en $\mathrm{BD}$ pour du café, au dessin réaliste, montre un propriétaire exaspéré menaçant de mort ses voisins qui laissent divaguer leurs poules (Marschall 1987: 38) ${ }^{15}$. Les banlieues américaines ont dû voir naître plus d'un conflit à ce sujet, et le jugement négatif porté en 1995 par les juristes sur les gallinacés parait intemporel.

Déjà, au début du siècle, Benjamin Rabier, le dessinateur animalier français par excellence, n'hésitait pas, dans une histoire intitulée «Le lapin de chou et le lapin de garenne ", à décrire la basse-cour comme une « société [qui] se compose d'êtres bêtes et stupides qu'on engraisse pour nourrir l'homme ». Dans un autre récit illustré, il qualifie la poule d'《idiote $»^{16}$. Le comportement des volailles fait l'objet de nombreux gags, ce, jusque dans la BD expérimentale. Quantité d'histoires se fondent sur leur bêtise supposée : ainsi, un coq et un canard pompon, animal de compagnie, se disputent un lutin en tirant stupidement dessus, comme sur un élastique (Figure 1); des auteurs ont même imaginé de remédier à ce défaut d'intelligence : dans une aventure de Spirou et Fantasio, une poule est le cobaye d'une expérience du savant comte de Champignac, destinée à multiplier par dix sa mémoire, son imagination et sa vivacité de raisonnement ${ }^{17}$. 


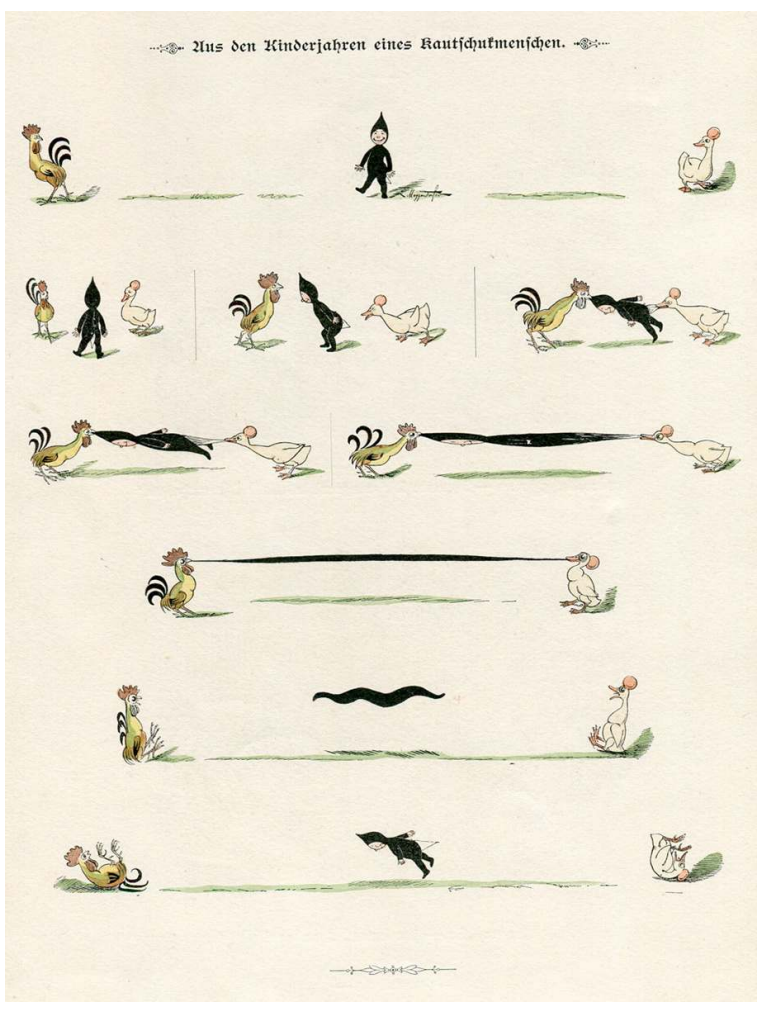

(c) Ancienne collection Pierre Couperie

\section{Une icône de la ruralité}

La poule et le coq sont des animaux très souvent mis en scène car ils jouent un rôle dans l'image que le $9^{\mathrm{e}}$ art veut donner des campagnes. Pas de paysan sans sa poule ${ }^{18}$ ! On voit des gallinacés dans les champs, les cours de ferme, l'étable où la poule tient compagnie aux vaches et à la fermière qui baratte le beurre. Au chaud dans la cuisine, la poule pond à volonté et, humour oblige, directement dans la poêle ${ }^{19} .$. Les histoires de volailles sont l'occasion de mettre en lumière des acteurs classiques du monde rural, respectables, comme le fermier, ou marginaux avec le coquetier, ou vendeur d'œufs ${ }^{20}$, et le voleur de poules. Celui-ci, image du sans-abri à toutes les périodes, est un motif constant d'inspiration pour une $\mathrm{BD}$ qui se révèle très souvent témoin de son temps ${ }^{21}$, mais dont l'humour parfois cruel s'exerce volontiers aux dépens des pauvres et des ruraux. Toute l'illustration $\mathrm{du} \mathrm{xIX}^{\mathrm{e}}$ siècle en témoigne $\mathrm{e}^{22}$ : la poule est là pour mettre en lumière la vulgarité du paysan en regard des jeunes lecteurs urbains ${ }^{23}$. Les magazines illustrés invitent d'ailleurs ceux-ci à fabriquer, à titre de "cadeaux amusants ", des figurines de paysans s'occupant de leurs poules et des œufs ${ }^{24} \ldots$ Les dessinateurs se montrent très tôt lucides sur le caractère caricatural de cette association, tel Steinlein qui, sous la forme d'un pastiche de dessin d'enfant, figure la vie à la campagne tout encombrée de poules et de poussins ${ }^{25}$.

7 La poule (associée au cochon) disqualifie également le "petit Blanc» de l'Amérique profonde, montré comme un être d'une stupidité sans fond, au moins égale à celle que les juristes imputent à la poule, et celle-ci a le même caractère de marqueur social au Japon. 
Dans un manga récent, un jeune fonctionnaire du ministère de l'Éducation, de la Culture et de la Recherche est envoyé en mission par le Premier ministre au fin fond des campagnes japonaises avec pour objectif d'inciter les élèves des lycées agricoles à choisir le travail de la terre pour carrière. Lui-même doit s'habituer à la ruralité, dont une des caractéristiques est non seulement de devoir se lever avec les poules, mais également de dormir avec elles ${ }^{26} \ldots$

\section{... et méchante?}

\section{Terreurs enfantines}

8 Même s'il ne s'agit que d'un animal «anodin » et banal, la poule peut faire peur. Dotés d'un bec pointu, adeptes du piquage, les gallinacés sont souvent perçus comme cruels. Les volailles nourrissent les cauchemars des personnages de BD. Ainsi la poule picore-t-elle la tête d'un dormeur en compagnie de ses poussins, tandis que des passereaux font leur nid dans la bouche de celui-ci, l'étouffant peu à peu (Canemaker $2005:$ 82, Winsor McCay 1977) ${ }^{27}$... Des volailles géantes et effrayantes sont souvent figurées dans la BD américaine des premiers temps, thématique reprise par un dessinateur franco-belge des plus classique, Cuvelier (Goddin 1984 : 113), aussi bien que par les comix de l'underground américain ${ }^{28}$. La BD expérimentale française fournit également des images phobiques "ornithoïdes", parmi lesquelles le poulet géant sans plume, né de souvenirs d'enfance traumatisants d'un dessinateur gardant en mémoire le spectacle du poulailler de son oncle, à CorbeilEssonnes, peuplé de poules agressives et de portées de poussins morts ${ }^{29}$.

9 Le comportement des gallinacés, vu par de jeunes enfants, donne à ceux-ci quelques raisons de les craindre. Tel est le cas de la jeune cuisinière Lucy Knicksley, attaquée dans son enfance par une poule "particulièrement vicieuse " parce que sa mère, "comme beaucoup d'éleveurs de poules débutants », avait « fait l'erreur d'acheter trop de coqs, ce qui rendait le poulailler particulièrement violent et effrayant $»^{30}$. Si l'on reconnaît aujourd'hui aux enfants le droit d'avouer leurs traumatismes, tel n'était pas le cas avantguerre. Dans la cour d'une ferme, encerclée par les oies, le coq et un cochon, une fillette apeurée se colle au mur de la grange en couverture du journal Lisette portant le titre accusateur de «Colette la peureuse $»^{31}$. 
Figure 2 : Benjamin Rabier, Le Coq, coll. L'Esprit des bêtes, s.d.

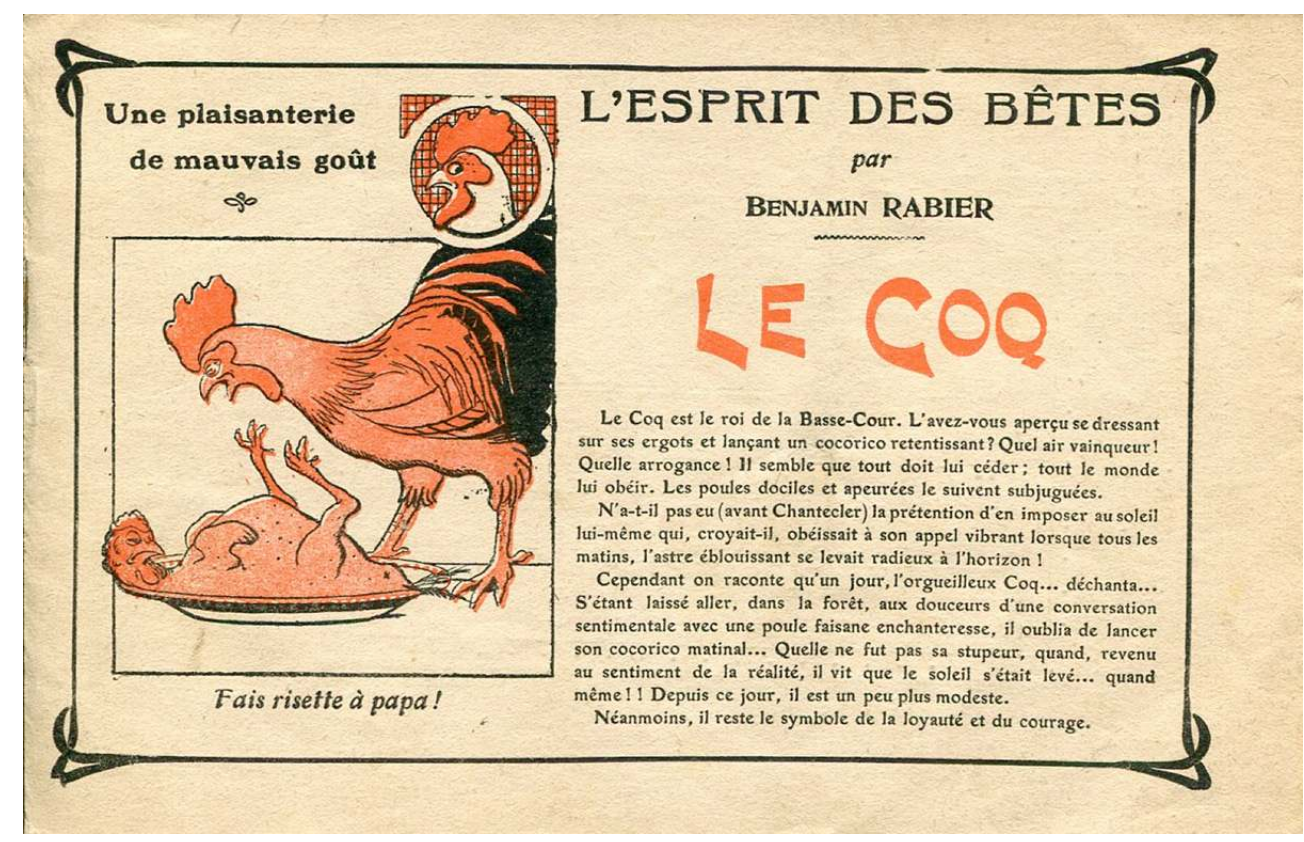

Figure 3 : Bisi, Corriere dei Piccoli, 10 année, n² 24, 16 juin 1918

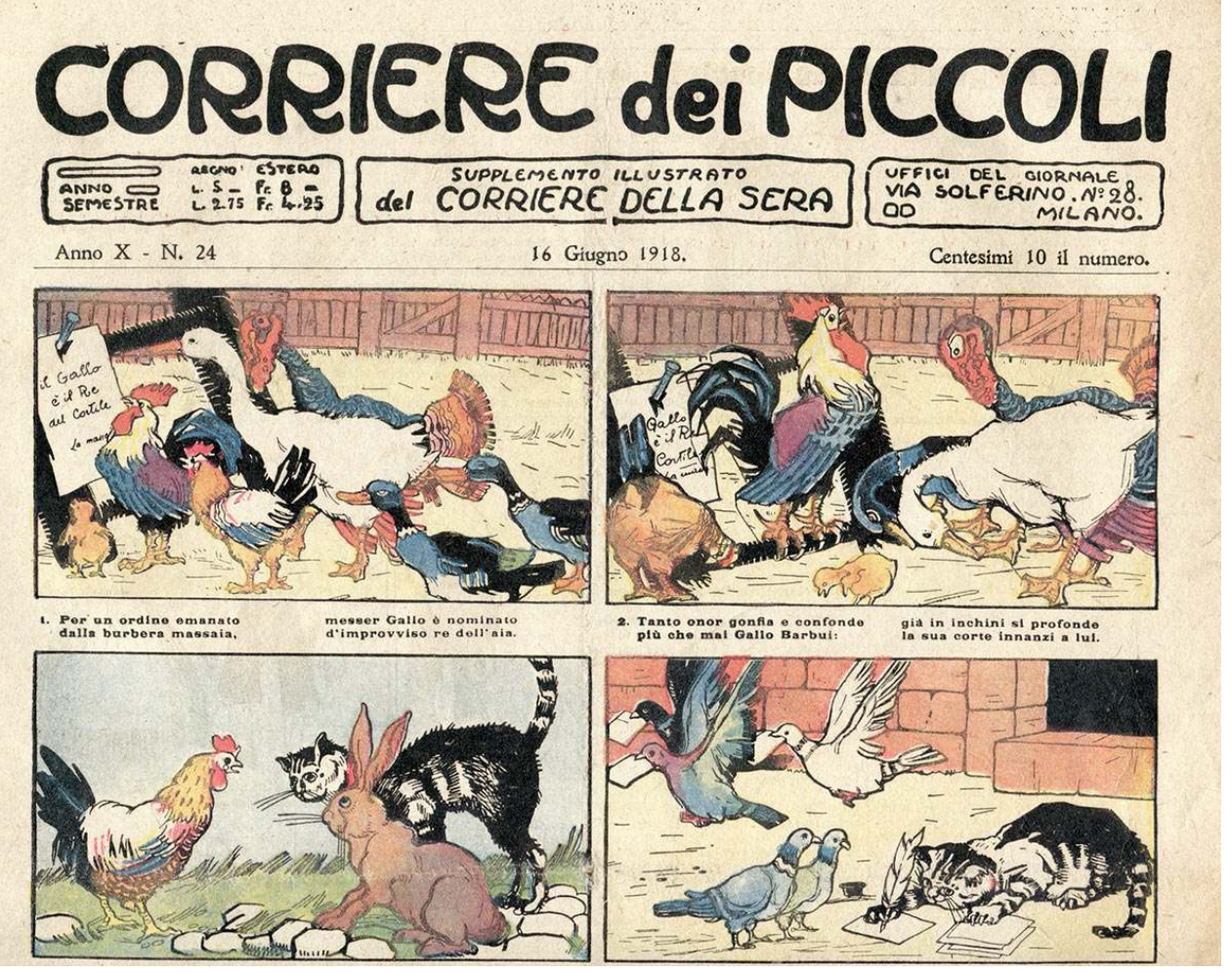

(c) Ancienne collection Pierre Couperie

C'est presque toujours le coq qui apparaît comme une figure effrayante, surtout aux yeux des tout-petits ${ }^{32}$. Grande figure de l'imagerie patriotique, ce volatile qui s'impose en couverture du Petit Buffon illustré3 est le roi de la basse-cour, comme l'expliquent aussi

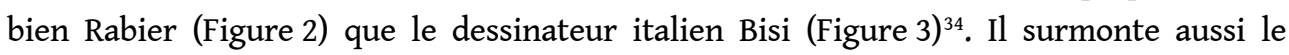


clocher de l'église ${ }^{35}$. Le mâle de l'espèce apparaît moins sympathique que la poule. "Arrogant», dit Rabier, violent, voire cruel, d'un caractère emporté, qualifié de «terrible», il a pour nom Furioso dans les aventures de Félix le chat ${ }^{36}$. A contrario, la poule est perçue comme un animal aimable : elle est dite «bonne » et ingénieuse chez Benjamin Rabier ${ }^{37}$, «industrious » et «avisée $»^{38}$ dans une histoire de Walt Disney. Jusque dans les années 1930, les poules et les poussins sont, aux yeux des enfants, de véritables peluches vivantes, et les fillettes, par ailleurs chargées de récolter les œufs ${ }^{39}$, s'installent volontiers au poulailler pour une séance de lecture ${ }^{40}$. Avant-guerre, choisir une poule ou un poussin comme compagnon de jeu et se prendre pour lui d'une "grande affection " n'avait rien d'extravagant ${ }^{41}$. Les poules trouvent même grâce aux yeux des lecteurs adultes. Mais seuls des êtres à l'âme enfantine, tel Gaston Lagaffe, le seul héros de BD humain à avoir lui-même couvé des œufs au poulailler ${ }^{42}$, ont adopté la poule comme animal de compagnie ${ }^{43}$.

11 L'intérêt pour l'éthologie des gallinacés, chez les auteurs de BD, est de toute évidence né d'une familiarité acquise au sein du poulailler familial. Enfants, les dessinateurs en herbe ont aimé observer les poules. Ainsi Gordon Bess note-t-il qu'elles doivent « renverser la tête pour boire $»^{44}$. Plus souvent, c'est la sexualité de la poule $e^{45}$ et celle, plus triomphante, du coq qui font l'objet d'observations humoristiques. Les mœurs douteuses de l'une sont pointées par Binet et Hausman $^{46}$, le dessinateur animalier par excellence depuis les années 1960, et le caractère d'obsédé sexuel de l'autre par Dimitri ${ }^{47}$ ou Gary Larson ${ }^{48}$. Les poules ne sont-elles pas l'objet des désirs sexuels de tous les oiseaux de la basse-cour, y compris le paon, comme dans l'histoire de la poulette enlevée par un paon «qui lui aura fait subir le supplice de la roue $\star^{49}$ ?

\section{La plus grande basse-cour du monde}

Les gallinacés ont tenu une place majeure dans le bestiaire enfantin, soit comme héros à part entière, soit comme animal familier, soit comme souffre-douleur. Si les animaux, et parmi eux les volailles, sont aussi présents dans la BD, c'est, pour paraphraser Thierry Groensteen qui la qualifie de "plus grand zoo du monde » (Groensteen $2000: 8$ ), qu'elle est assurément la plus grande basse-cour de l'univers. La BD est ici l'héritière directe d'un genre antique et médiéval, celui de la littérature animalière, diffusé grâce aux fables d'Ésope, puis au Roman de Renart (Denoyelle 2014) ${ }^{50}$, dont découle directement le goût pour la représentation d'animaux anthropomorphes dans l'illustration (Benjamin Rabier 1981 : 23) et la bande dessinée (Morgan 2000).

\section{Humain, trop humain}

Tout autant et tout aussi bien que la littérature classique (Loetscher 1994), la BD fait montre d'un goût affirmé pour les thèmes philosophiques de l'humanisation de l'animal - et de l'animalisation de l'homme. Benjamin Rabier, l'auteur de loin le plus prodigue en représentations animales dans toutes les formes de littérature illustrée, multiplie les histoires de canards, d'oies, de poussins, de poules et de coqs : en témoignent Tintin le petit poussin ${ }^{51}$, Marius, coq du clocher, "Cocorico et Blanchette », etc. Sur ce plan, le $9^{\mathrm{e}}$ art doit beaucoup à la littérature enfantine. Des romans illustrés entiers sont consacrés aux gallinacés, dont les héroïnes sont des poules blanches, grises, noires ou rouges ${ }^{52}$; la célèbre histoire de La Petite poule rousse, récemment mise en bande dessinée pour les tout- 
petits ${ }^{53}$, a même inspiré la carrière de Cécile Boulaire qui avoue devoir à ce récit sa vocation de chercheuse en littérature de jeunesse ${ }^{54}$. Des "p'tites poules» pleines d'humour distraient encore les enfants du $\mathrm{xxI}^{\mathrm{e}}$ siècle $^{55}$. En vérité, les gallinacés sont omniprésents dans le paysage de l'enfance: ils s'imposent non seulement dans la littérature de jeunesse, mais aussi dans les jeux d'extérieur ${ }^{56}$ ou d'intérieur ${ }^{57}$ ainsi que dans les objets alimentaires enfantins (Benjamin Rabier 1981 : 15).

\section{Poulets farceurs}

Jouets vivants, les gallinacés font souvent les frais des farces enfantines. Le prototype des histoires de petits farceurs, Max und Moritz, débute par une histoire de volailles qui fait l'objet des deux premiers "exploits» de ces affreux garnements (Wilhelm Busch [1865] 1966 : 11-34). Livrés à leurs agissements, trois poulettes à la queue en point d'exclamation et leur coq "fier en voix", appartenant à une honorable veuve, finissent pendus à une ficelle, excrétant un œuf (pour les poules) et une crotte (pour le coq), triviale expression de leur dernier souffle (Figure 4). Après les avoir pleurés amèrement, la veuve n'a d'autre choix que de les mettre à cuire en fricassée avec du beurre (selon la traduction de Cavanna) ou simplement rôtis (selon celle d'André Thérive) ${ }^{58}$.

Figure 4 : Wilhelm Busch, Max et Moritz, 1865

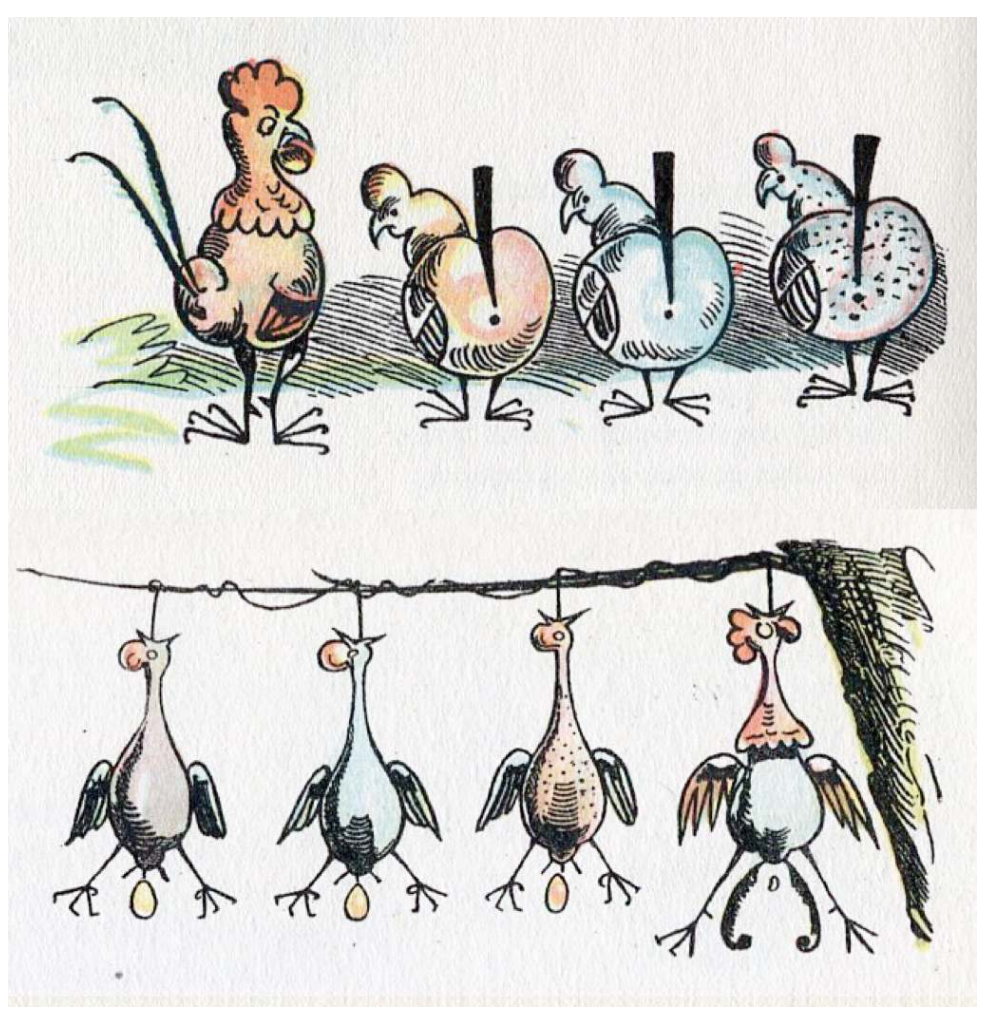

Le temps d'aller à la cave chercher de la choucroute pour accompagner ce festin, les volailles cuites à point sont volées par les vilains enfants. Le crime ne reste pas impuni. À la fin de l'histoire, les enfants sont mis en pâte et cuits dans le four du boulanger puis... émiettés et donnés à manger aux canards du meunier... 


\begin{tabular}{|l|l|}
\hline «L'élevage des poulets & « Les bonnes gens pour leur volaille \\
\hline A, c'est certain, des attraits. & Prennent bien du soin et travaillent. \\
\hline Pour les œufs premièrement, & D'abord pour récolter des œufs \\
\hline Que ces oiseaux vont pondant & Que pond ce bétail peu coûteux. \\
\hline Ensuite, une poule-au-pot & Ensuite on peut mettre sur table \\
\hline Améliore le fricot. & Souvent des rôtis délectables. \\
\hline Et troisièmement, enfin, & Tertio, on aime à recueillir \\
\hline N'oublions pas les coussins, & Les plumes dont on va garnir \\
\hline Non plus que les édredons, & Oreillers, édredons et couettes \\
\hline Doux aux reins, chauds aux petons, & Pour tant de personnes douillettes \\
\hline Que nous offre l'animal.» & Qui craignent d'avoir froid au lit ${ }^{59}$ •» \\
\hline
\end{tabular}

Max et Moritz ont directement inspiré un autre couple de démoniaques petits farceurs, les Katzenjammer Kids, de John Dirks (Marschall 1997 : 16), série connue en France sous le nom de «Pim Pam Poum» dans les années 1950, et de «Capitaine Cocorico » dans les années 1930. Dans cette série de très longue durée (plus d'un siècle et d'un auteur), ces enfants terribles ne cessent de prendre les animaux comme souffre-douleur et, parmi eux, les canards, zébrés de peinture, les poules, plumées ou montées sur des ressorts ${ }^{60}$, etc.

\section{Le cheptel}

\section{Un corpus titanesque}

17 Au sein d'une iconographie qualifiée par Pierre Couperie de «titanesque " (Couperie $1997: 131)^{61}$, et en prenant en considération le panorama mondial de la BD, tant européen qu'américain, australien et même asiatique - grâce aux mangas -, nous avons constitué un fort cheptel d'histoires de gallinacés: le corpus, par définition non clos car en perpétuelle expansion, approche les 1500 occurrences. Nous n'avons pas écarté les cousines germaines de la BD, telles les imageries d'Épinal, de Nancy ou de Paris, qui offrent d'assez nombreuses histoires de poules et de coqs ${ }^{62}$. Mais nous avons éliminé presque tous les dessins humoristiques, constitués d'une seule case, au profit des histoires séquentielles qui permettent de mieux cerner le rôle joué par les gallinacés dans le paysage social. De même, nous avons choisi de ne traiter que les gallinacés au naturel, leur évitant l'indignité d'apparaître « dans le ridicule appareil d'une volaille plumée » ${ }^{63}$.

Le corpus provient essentiellement du domaine franco-belge (63\%) et des USA (20\%). 7 \% des histoires proviennent de Grande-Bretagne, $6 \%$ d'Italie et $4 \%$ de diverses nations, chacune faiblement représentée (Argentine, Brésil, Japon, Finlande, Espagne, Allemagne). 
Les histoires se déroulent dans le monde contemporain, mais proviennent aussi de récits historiques à raison d' $1 / 10^{\mathrm{e}}$. La présence des poules est le plus souvent anecdotique $(70 \%$ des cas), mais $28 \%$ des histoires du corpus ont un gallinacé pour héros ou personnage clé, soit dans une histoire longue ou une série (12\%) soit dans une histoire courte (16\%). Dans $2 \%$ des cas, les gallinacés apparaissent sous la forme d'animaux composites ou hybrides, à la manière du coq-théière d'un magazine anglais des années 1890. (Figure 5)

Figure 5 : J. B. C., « Mr. Turnip's Complaint », Little Folks, A Magazine for Young People, n 37, 1893 (ou 1898)

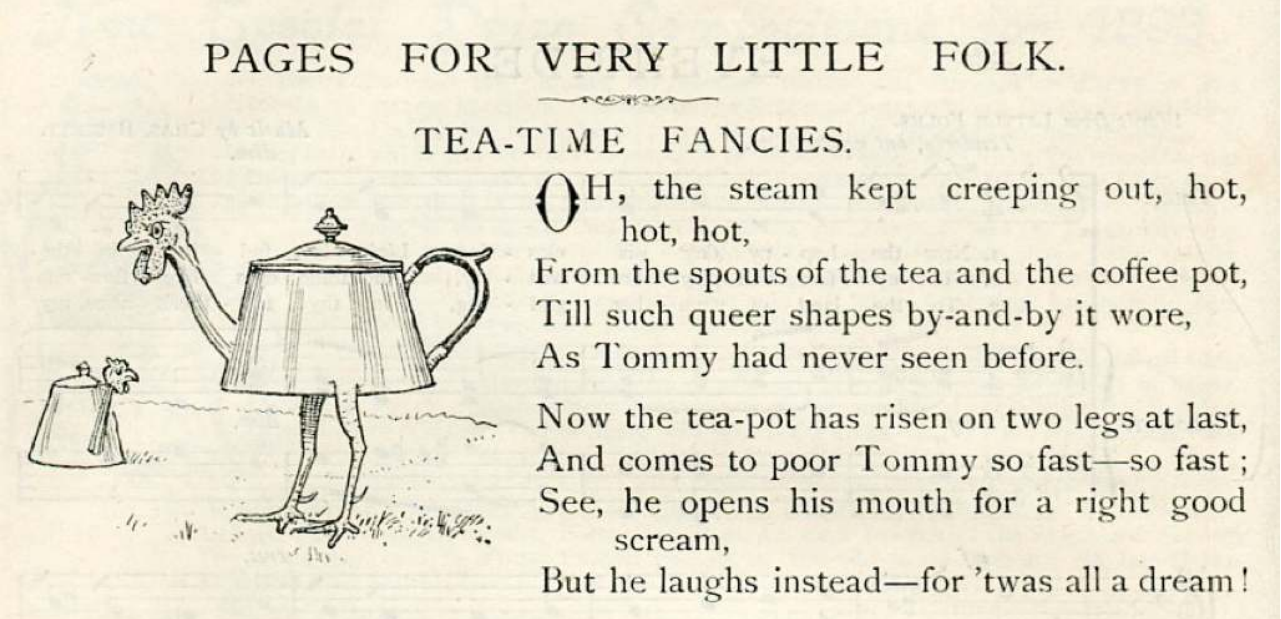

Poules et coqs se pavanent volontiers sur les couvertures des illustrés et, dans $12 \%$ des histoires où s'ébattent des gallinacés, les titres affichent les mots de poule, coq, poulet ou œuf, témoignant de leur succès d'audience. Plusieurs séries ou magazines illustrés, tant satiriques ou politiques ${ }^{64}$ qu'à destination des enfants, ont même pris le nom d'un gallinacé pour titre : Cocorico, Chick's Own, qui a pour héros récurrent « Rupert the Chick », Poules à lier, Poules rebelles, Poussin $\mathrm{I}^{\mathrm{er}}$, Le Petit CEuf, etc.

$\mathrm{Au}$ sein de ce cheptel de papier, les gallinacés sont largement majoritaires. Ils représentent $37,5 \%$ du total, devançant les canards ( $25 \%)$, les oies $(10,5 \%)$, le pigeon $(1,1 \%)$, le paon $(0,5 \%)$ et même le dindon $(7,5 \%)$, présent surtout dans la BD américaine à l'approche du Thanksgiving Day et dans la BD anglaise pour Christmas. La poule est deux fois plus souvent figurée que le coq. Les poussins, auxquels peuvent s'identifier les enfants, ne représentent que $2 \%$ du corpus. Les œufs sont présents dans $4 \%$ des cas. Ils sont l'objet de gags multiples (Alexandre-Bidon 2017): ils sont fragiles, et les petits farceurs des bandes dessinées en cassent partout et en grand nombre ${ }^{65}$. Anthropomorphes, ils jouent un rôle non négligeable dans l'imaginaire enfantin, avec pour modèle le personnage de Humpty Dumpty, issu d'une nursery rhyme et intégré par Lewis Carroll dans les aventures d'Alice au pays des merveilles. Ces œufs humanisés font partie depuis le XIX ${ }^{e}$ siècle des héros de la littérature enfantine anglo-américaine. Dans le domaine franco-belge, très catholique, les œufs s'imposent à la période pascale, car les magazines illustrés pour la jeunesse collent au calendrier festif. En mille neuf cent quatre-vingt... neuf est même publié, pour la rime, un livre de circonstance, un recueil collectif d'histoires d'œufs ${ }^{66}$. La cuisine de la poule et de l'œuf, avec $17 \%$ des occurrences de gallinacés, mériterait un article à elle seule, donnant à voir l'évolution des recettes et, toutes époques confondues, l'écrasante prédominance du poulet rôti, icône du repas familial. 
L'ensemble permet de tirer de la BD des conclusions sur le ressenti des humains envers leurs volatiles familiers. Le corpus fait montre d'une sensibilité plus forte envers l'animal femelle, maternel et nourricier, qu'à l'encontre de la bête mâle, symbolique, politique - et agressive. De toute évidence, la poule est la volaille préférée des enfants. Si les canards ont fini par l'emporter dans les esprits, avec l'inénarrable Donald qui fut lui-même éleveur de poulets (Groensteen 1987: 48), il n'était à l'origine qu'un personnage secondaire : Donald Duck, qui apparaît en $1934^{67}$, provient d'une série inspirée d'un dessin animé et dédiée, non à lui, mais à une mère poule avisée, "The Wise Little Hen », traduite en français et publiée en première page du tout nouveau Journal de Mickey (Groensteen $1987: 47)$.

\section{Esthétique des gallinacés}

À l'instar du paon, poules et coqs sont aussi appréciés des artistes pour la beauté de leur plumage - que les humoristes font déplumer par les jeunes plaisantins ${ }^{68}$ ou par les amoureux : Mickey plume un coq comme on effeuille la marguerite pour savoir si Minnie l'aime vraiment ${ }^{69}$. Les gallinacés ont souvent été pris pour modèles par des peintres et dessinateurs de haut niveau: Ernst Stein ${ }^{70}$, Caran d'Ache, Mucha qui, à la fin du XIX siècle, le dessine sur la têtière du journal Cocorico dont chaque couverture est dédiée à ce volatile dressé sur ses ergots.

La poule serait-elle une muse pour les dessinateurs? Au XIX ${ }^{e}$ siècle, déjà, des artistes dissidents avaient choisi la femelle de l'espèce pour porter haut la bannière des "arts incompris", ainsi à Bourg, patrie de la poularde de Bresse (Arts incompris 1887). Les dessinateurs underground et les artistes les plus contemporains passent volontiers eux aussi par la case basse-cour. L'esthétique des gallinacés joue à l'évidence un rôle dans le choix du sujet par les artistes. La plastique remarquable du coq est traitée dans le style de chaque période : Art Nouveau avec Mucha, à la fin des années 1890 (Figure 6) et au début des années 1900 , constructiviste dans les années $20^{71}$, futuriste dans les années 30 pour la revue fasciste Il Balilla ${ }^{72}$, cubiste pour la revue italienne If $^{73}$, underground dans les années $1970^{74}$, expérimentale depuis la fin des années $1980^{75}$.

Figure 6 : Têtière de Cocorico, dessinée par Mucha

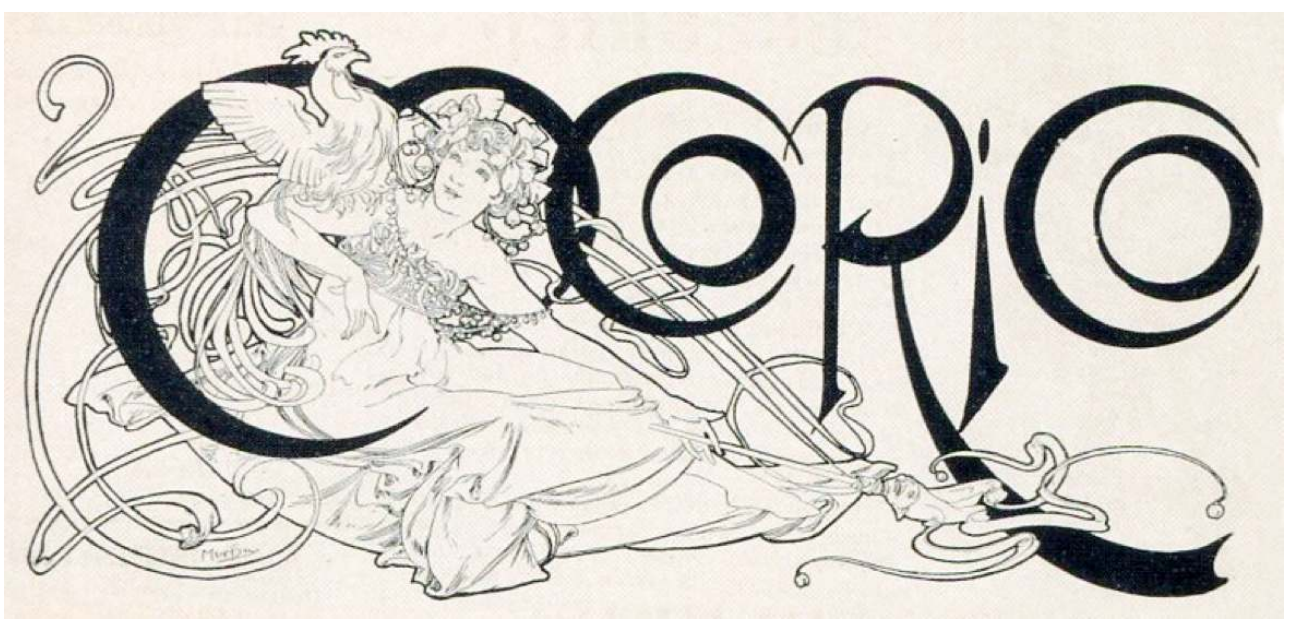

Le jeune lecteur est lui aussi jugé capable d'apprécier la beauté d'un plumage : le coq de Kochi lui est présenté « pour le plaisir des yeux $»^{76}$. Dépeindre les gallinacés intéresse les 
artistes de BD pour plusieurs autres raisons : l'envol des volailles devant un cheval au galop, une bicyclette, une voiture, voire un avion à l'époque héroïque ${ }^{77}$, un grand classique de la bande dessinée, offre aux dessinateurs l'occasion de mettre en évidence leur habileté à représenter la vitesse et l'arrêt sur image. Parce que les gallinacés sont les témoins privilégiés des faits et gestes des humains, dans la remarquable série " Magasin Général ", la scène est parfois vue à hauteur des yeux de la poule, selon un procédé original et innovant dans le récit visuel ${ }^{78}$. Enfin, l'humour a aussi son mot à dire dans la prédilection pour le sujet. La poule est souvent dépeinte comme ridicule, notamment au moment de la ponte; le coq a ses personnages emblématiques mais ambigus, tel le clown à l'habit brodé de coqs (Figure 7), héritier direct du fou médiéval au chaperon en coquecigrue $^{79}$.

Figure 7 : Van Beers, couverture de Rires et grimaces, par Forain, Caran d'Ache, Pille, Willette, Godefroy, Guillaume et Fau [1890]

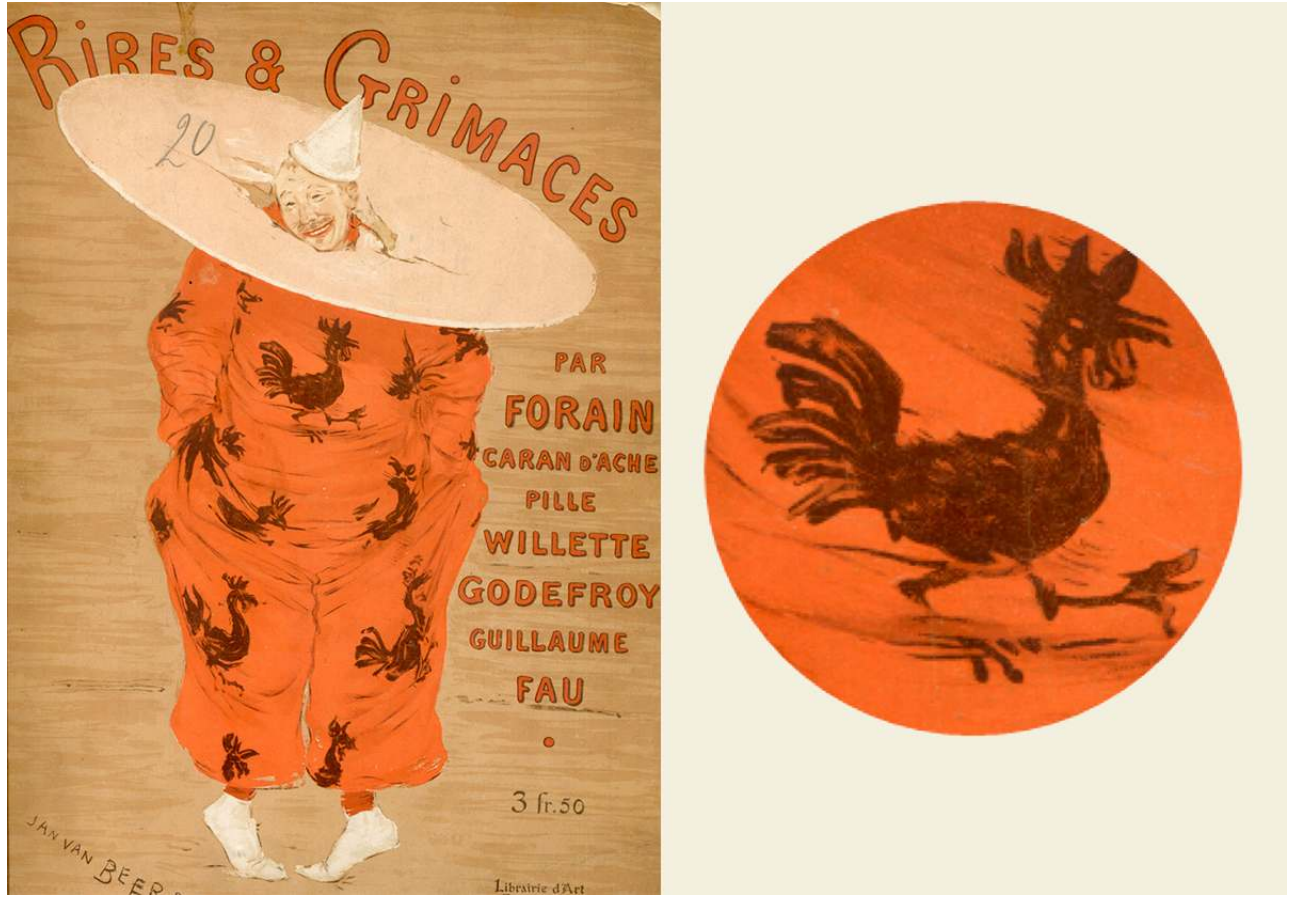

\section{La poule, animal social}

Omniprésentes, les poules sont des animaux sous-estimés, dans la réalité comme dans la bande dessinée. On nous pardonnera donc, pour décliner leur existence de papier et contredire chemin faisant leur réputation de sottise, de leur rendre hommage en pastichant Aristote, lui-même auteur d'une Histoire des animaux et qui s'est interrogé sur l'œuf et sur la poule, et en examinant leur rôle social à travers leur Éthique, leur Politique et leur Économique... 


\section{Éthique}

\section{Mauvais genre} par le biais de l'anthropomorphisme. Les poules de BD portent habituellement des prénoms féminins : Clara Hen chez Disney, Henny Penny chez Walt Kelly, Clothilde dans le «Chlorophylle » de Wally et Bom, Emma la poule dans une histoire de Watch et Bom, Dorothée dans une histoire du journal Tintin... Un effet de symétrie inverse veut que des héros humains de BD aient des noms de gallinacés, tels "Le capitaine Cocorico", traduction peu respectueuse des Katzenjammer Kids, sans parler des Monsieur Poulet ou Poulness, ou encore de Théodore Poussin qui, pour ses débuts, naît d'un œuf et sort d'un coquetier en couverture du journal Spirou ${ }^{80}$.

\section{Histoires de poulettes}

Cet anthropomorphisme n'est pas sans ambiguïté : en français comme en anglais, poulette et jolie femme ne sont qu'un seul et même objet de la convoitise masculine. La langue vulgaire le montre bien, lorsqu'un homme s'adresse à une femme en lui disant: «Ma poule $»^{81} \ldots$... L'assimilation du couple paysan au duo coq et poule est d'ailleurs affirmée dès l'imagerie d'Épinal, toujours soucieuse de donner une leçon au genre féminin, qui doit en prendre de la graine. Dans une planche intitulée "L'esprit des bêtes ", le comportement des gallinacés est appliqué aux liens du mariage: la femme doit obéissance au mari comme la poule au coq. L'époux se permet donc d'affirmer à sa femme : « [...] je vais vous répondre comme le coq à ses poules $»^{82}$.

La métaphore est filée par tous les auteurs, avec plus ou moins de vulgarité ${ }^{83}$. Christophe ne manque pas de comparer les femelles de la famille Fenouillard à des poules et des oies - blanches, comme il se doit, pour les demoiselles ${ }^{84}$. Quand, en 1914, Illico, le père de famille brimé par son épouse, rêve de "chickens» ou quand, en 1921, deux cyclistes admirent « deux bath poules » ${ }^{85}$, il ne s'agit certes pas de poulets ou de poulettes mais de donzelles (McManus 1977). À travers l'image de la poule de BD, on lit souvent une dévalorisation du genre féminin. Les poulettes ne sont pas des héroïnes mais, par exemple, une prostituée ${ }^{86} . .$. Entre l'imagerie d'Épinal et la libération de la poule, alias la femme $^{87}$, la route sera longue! Néanmoins, toutes les poules ne sont pas sexuellement exploitées. Henrietta, dans "Chantecler », en 1911, est une suffragette qui n'hésite pas à demander à son époux de garder les poulets - les enfants - pendant qu'elle va manifester (Blackbeard \& Williams 1977 : 56). Une poule peut même remplacer une épouse, du moins au Moyen Âge. Aldegonde est ainsi l'objet d'un dialogue ininterrompu entre un paysan pauvre et elle dans un album de la série Les Tours de Bois-Maury ${ }^{88}$. Plus folklorique, et proche du thème des volaillères dans la peinture des $\mathrm{XVI}^{\mathrm{e}}$ et $\mathrm{XVII}^{\mathrm{e}}$ siècles ${ }^{89}$, Jean-Claude Servais, dans La Belle coquetière, pose comme les peintres de genre qui l'ont précédé l'équivalence entre la préparation des poules et la consommation sexuelle dans une histoire qui se déroule dans les campagnes du $\mathrm{xVIII}^{\mathrm{e}}$ siècle $^{90}$.

\section{Querelles de clocher}

Dans un tout autre genre, le poulet peut devenir une figure du religieux. Dans un contexte de libération des mœurs et surtout de liberté de pensée, les Américains des années 1960 
ont mêlé au divin la figure du gallinacé sous les espèces d'un poussin théologien ${ }^{91}$. Les Français se contentent, au xxI ${ }^{\mathrm{e}}$ siècle, de faire de la philosophie de basse-cour ${ }^{92}$, riche en aphorismes empruntés à d'autres penseurs, tel Samuel Butler : "Une poule n'est rien d'autre que le meilleur moyen qu'a trouvé un œuf pour faire un autre œuf. »

Il faut attendre les années 2010 pour voir un coq se prendre pour Jésus, occasion de fables sur l'antisémitisme. "Je suis un coq. Et je suis également la réincarnation de Jésus " ${ }^{93}$. Cette image du poulet crucifié rappelle étrangement certains exempla médiévaux ${ }^{94}$. Un dieu, et non des moindres, peut encore s'incarner dans un poulet : Zeus, ainsi figuré dans un manga ${ }^{95}$. Le volatile, qui a le don de la parole, assure la protection du héros, son fils. Le coq, oiseau du soleil par excellence, est un choix logique pour le roi des dieux. Même la poule est investie d'un rôle chrétien, que diffuse la BD catholique avec l'exemple de la dévotion de saint François. Le saint a la vision de ce volatile maternel, entouré de quatorze poussins, trop pour qu'elle puisse les protéger sous ses ailes - un thème de prédication classique au Moyen Âge ; de même, dans la BD, François ne se sentait-il pas capable de protéger tous ses frères franciscains, et demanda-t-il au pape de nommer un cardinal à cette fin. On est là dans la lignée de l'image du Christ en poule protectrice des fidèles, tel que nous le montrent à la fois les exempla et des gravures du XVI ${ }^{e}$ siècle $^{96}$.

\section{Politique}

31 Le goût prononcé pour l'anthropomorphisme animalier explique que les gallinacés soient non seulement des figures exemplaires du religieux, mais aussi des personnages clé de l'iconographie politique. Le dessin humoristique et la bande dessinée sont ici encore les héritiers directs de l'iconographie médiévale et moderne. Depuis la fin du $\mathrm{Xv}^{\mathrm{e}}$ siècle, le coq est l'emblème de la royauté avant de devenir celui de la République. Des gallinacés, pris tantôt en bonne part, tantôt en mauvaise part, se trouvent très anciennement dans des pamphlets: un parti flamand se baptise sous le nom de Kiekefretters, c'est-à-dire "mangeurs de poules", épisode que rappelle d'ailleurs la BD médiévalisante "Bec-enFer ", série dont tous les personnages sont des poulets ou autres oiseaux de basse-cour ${ }^{97}$ - la biographie de l'auteur nous apprend qu'il était le neveu d'un éleveur de poules à Écuillé, dans le Maine-et-Loire (Derouet 2011: 17). On trouve encore, en 1600, au cœur d'un conflit opposant la Savoie à la France, l'histoire d'une poule savoyarde qui se veut la métaphore du duc Charles Emmanuel $\mathrm{I}^{\mathrm{er}}$ face au coq français, alias le roi de France, car « la Poule veut le Coq, aussy veut la Savoie » (Harai 2006).

\section{Combats de coqs}




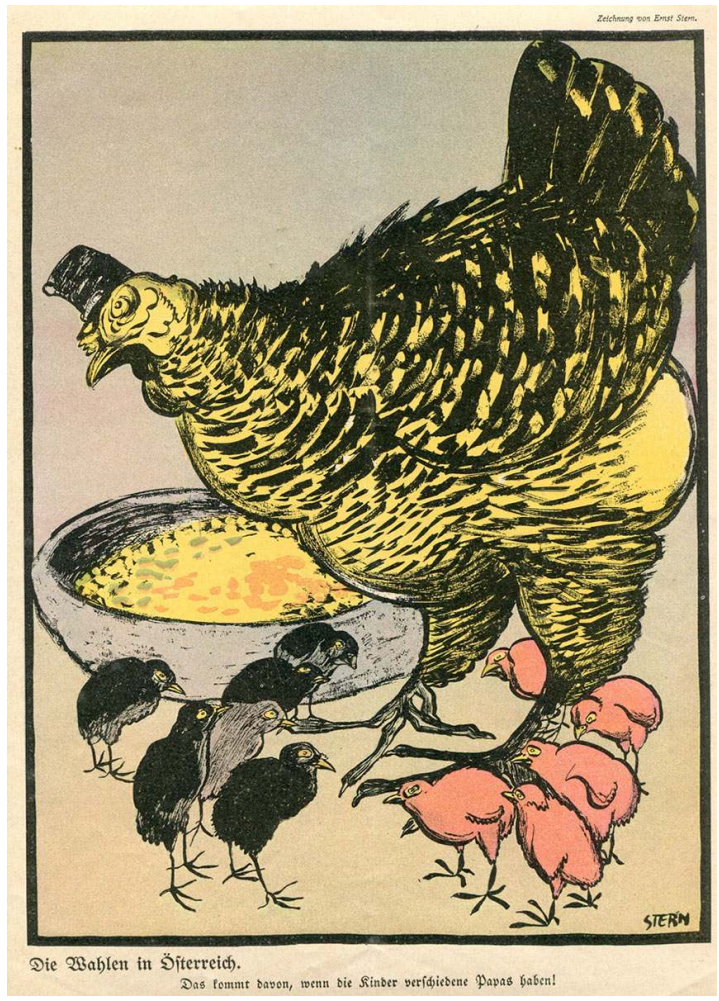

Pour autant, l'image du gallinacé n'est pas exclusive du nationalisme gaulois. La poule est aussi utilisée à l'occasion d'élections. Au début du xxe siècle, en Autriche, elle apparaît comme la métaphore de cette nation (Figure 8), ses poussins aux diverses couleurs de plumage représentant les différents partis ${ }^{98}$. En France, les illustrateurs de livres d'histoire pour la jeunesse, tel Job, choisissent le coq pour emblème politique, comme allégorie de la nation française ${ }^{99}$ ou symbole de ses représentants les plus méritants, tel Guizot $^{100}$. L'oiseau est nécessairement cocardier ${ }^{101}$. Dans un album de théâtre d'ombre, sous le nom (médiéval) de Chanteclair, il incarne la défense de la terre natale pendant la Grande guerre ${ }^{102}$, figure du Gaulois forcément victorieux du Barbare germanique. Quand il salue le soleil levant, il annonce la Victoire que l'on veut croire imminente (Figure 9).

Figure 9 : Henriot, Les Poilus à travers les Ages, ombres et poëme, Paris, Berger-Levrault, 1917

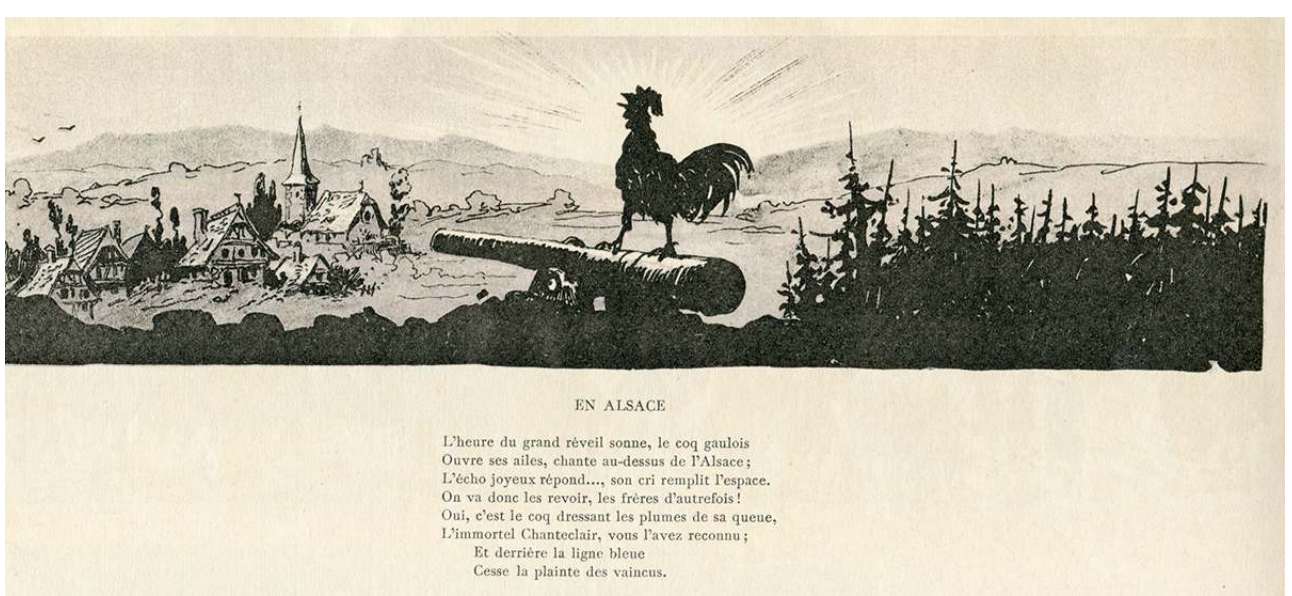



de l'ours, qui symbolise la Russie, du léopard, pour la Grande-Bretagne, et de l'aigle pour l'Allemagne (Benjamin Rabier 1981 : 28). Son image orne les pièces de monnaie, ces «tracts métalliques »; présentisme oblige, le coq s'affiche encore dans la copie d'une affiche de propagande de 1917 exigeant des Français : « Pour la France, versez votre or. L'or combat pour la victoire ", dessinée dans une BD destinée à "dénoncer les faux-semblants du libéralisme » et la « nouvelle économie »104.

Le coq combattant est une constante de l'imagerie patriotique française. Il est sorti vainqueur de la Première Guerre mondiale, perché sur un casque à pointe, en frontispice des journaux de tranchées illustrés, ainsi pour Notre Rire ${ }^{105}$. Il a rempilé pour la Seconde. Fin 1939, il est associé au pompon bleu blanc rouge des marins ${ }^{106}$. Un journal émis par un résistant dès avant la Libération (Coq Hardi 1981, Coq Hardi s.d.) lui doit son titre, héraldique : Coq hardi. Ce journal de BD, publié en zone Sud de novembre 1944 à février 1945, avant de reparaître en 1946, affichait la figure glorieuse d'un coq au bec grand ouvert, avec, pour sous-titre, "chante tous les dix jours pour la jeunesse de France " (Figure 10).

Figure 10 : Têtière de Coq hardi, 1950

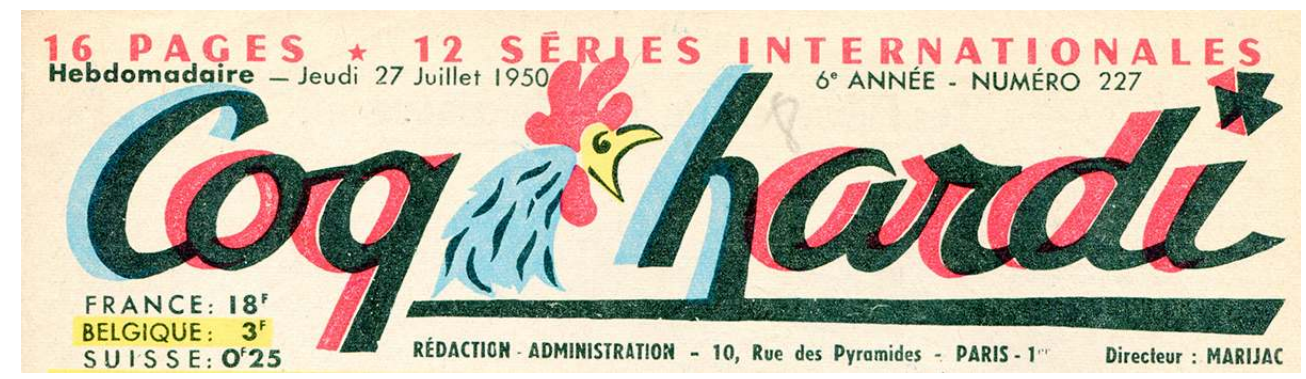

Dans l'iconographie, de François I ${ }^{\text {er }}$ à nos jours, le coq, animal combatif, est « de fière allure $»^{107}$, « fier et gaillard $»^{108}$, « symbole de la loyauté et du courage $»^{109}$. C'est pourquoi les héros chevaliers de la bande dessinée n'hésitent pas à le prendre comme meuble héraldique ${ }^{110}$. La parodie offre à ce volatile agressif le rôle de " poulet de guerre ", comme dans la reconstitution animalière de la bataille de Hastings par Joann Sfar ${ }^{111}$, motif à l'évidence inspiré des combats de coqs médiévaux. Il n'en finit pas moins par s'abâtardir. Évolution de l'Histoire oblige, le coq français emblématique des rois devient aussi celui de la bourgeoisie industrieuse. C'est l'animal entrepreneur, celui qui se lève tôt. À l'Exposition de 1889, le chapeau haut-de-forme de monsieur Fenouillard s'envole pour venir couronner un coq de fonte surmontant les toits des pavillons (Moliterni $1980: 23$ ). Un siècle plus tard, le coq a encore infléchi sa trajectoire: il accompagne désormais parodiquement la figure du Français moyen avec «Superdupont », le super-Français de Gotlib, qui, du geste auguste du fauconnier, tient avec superbe un coq sur le poignet ${ }^{112}$.

\section{Coqs de village}

Aux États-Unis, le coq est d'abord emblématique de la réussite sociale. Lointain écho des rodomontades des coqs de village, dans la ferme idéale dessinée en 1905 par R. F. Outcault pour un épisode de la vie mouvementée du jeune Buster Brown (Blackbeard \& Williams 1977 : 25), l'un des coqs, perché sur le barreau supérieur de l'échelle du poulailler, ne manque pas de le souligner avec fierté, dans une bulle: «I've reached the top of the 
ladder ", leçon de morale pour les jeunes lecteurs qui sont au sommet de l'échelle sociale et risquent fort de devenir de jeunes coqs prétentieux ${ }^{113}$. La même baisse de respectabilité qu'en France s'observe dans les USA des années 1970 : la poule, industrialisée, est aussi dévalorisée. Elle sert de chien d'aveugle à une Noire âgée et aveugle usée par l'économie volaillère du vieux Sud (Daniels 1971: 101) ${ }^{114}$. Ce jeu de miroir social entre l'homme et le gallinacé est décliné tout au long du $\mathrm{xx}^{\mathrm{e}}$ siècle. Chantecler Peck, flanqué de sa poule suffragette, affiche ses problèmes de couple dans The New York World en 1911 (Blackbeard \& Williams 1977: 56). Un autre, Chicchirichi, incarne la figure du prolétaire aux aspirations bourgeoises dans l'Italie des années 1950 (Groensteen 1987: 127). Un troisième est titré: le "marquis Chantecler de Barnevelt, poète et ami des arts » (Groensteen 1987). Déjà, au début du xx siècle, le coq s'affichait à la cour ${ }^{115}$ et la société parisienne huppée était représentée sous la forme d'une basse-cour emplumée ${ }^{116}$.

\section{La Guerre froide des gallinacés}

37 L'anthropomorphisme politique des gallinacés atteint un premier sommet au milieu du $\mathrm{xx}^{\mathrm{e}}$ siècle avec la fable politique de George Orwell, Animal Farm. Dans cette satire de la Révolution russe, publiée en 1945 , la toute première phrase met en scène un fermier ivre fermant à clé le poulailler, symbole de la réduction en esclavage des hommes par d'autres hommes (Orwell [1945] 1970: 5). Les poules jouent un rôle déclencheur: elles sont à l'origine de la prise de conscience de l'oppression; réduites à une obéissance aveugle et à un travail épuisant par les animaux dominants, les cochons, elles sont les premières à se rebeller et les premières aussi à souffrir de l'épuration qui s'ensuit. Dès la mort d'Orwell, en 1950, cette fable antistalinienne est adaptée en dessin animé par l'Atelier de la guerre psychologique de la CIA, puis, toujours à des fins de propagande, en bande dessinée, cette fois en Grande-Bretagne, sous l'égide de l'Intelligence Research Department. Cette BD, fidèle au roman d'Orwell, a été aussitôt diffusée sous forme de strips quotidiens dans les journaux de nombreux pays (en Asie du Sud-Est, Amérique latine, Inde, Afrique...) afin de combattre le communisme (Marcolini 2016) ${ }^{117}$. Elle l'était encore à cette fin au milieu des années $1970^{118}$.

Le nombre des BD animalières ne cesse de s'accroître au fil du $\mathrm{xx}^{\mathrm{e}}$ siècle ${ }^{119}$, révélateur probable du sentiment d'une brutalisation croissante du monde et d'une bestialisation de l'homme en tant qu'animal social. Lui faire jouer un rôle en termes animaliers, particulièrement sous les traits des gallinacés, permet de mettre en évidence son défaut d'humanité (Guichet 2006). Nombreuses sont les histoires, tant biographiques que politiques, qui adoptent le masque du gallinacé pour mettre en lumière la souffrance de minorités se sentant les victimes d'un sentiment d'exclusion: les Bretons ${ }^{120}$, les PiedsNoirs $^{121}$, le genre... Dans cette ménagerie de papier où la basse-cour symbolise de longue date la société humaine ${ }^{122}$, les poulets font parfois figure de victimes expiatoires. Jack Gallo, le coq héros inventé par le Philippin Gerry Alanguilan dans Elmer, est le représentant d'un monde où, à la suite d'une maladie aviaire, les gallinacés, subitement dotés d'une conscience, sont devenus "humains" (Gris 2014). Poules et coqs aspirent désormais à vivre à égalité avec l'espèce humaine, jusqu'à pratiquer le mariage interespèces. Mais ils souffrent d'inégalités sociales, de difficultés d'intégration et font les frais de la xénophobie ambiante. Il faut créer un Comité pour l'intégration des poulets. C'est l'occasion d'une fable philosophique sur la peur de l'autre ${ }^{123}$, mais aussi sur les violences sexuelles et l'homophobie ou encore sur la ségrégation raciale dans le monde du travail... 


\section{Économique} de substitution. En temps de paix, ils constituent une promesse d'approvisionnement en œufs frais, bons pour l'élevage des jeunes enfants. Élever des poules en ville ou en banlieue, avant l'âge du réfrigérateur, offre aux marchands de produits laitiers la possibilité de vendre des œufs du jour à la clientèle bourgeoise et méfiante du milieu des années 1930, qui exige de disposer, en ville, de «nice fresh eggs» (Betty Boop 1975) que la BD montre très tôt en vente au rayon épicerie des grands magasins américains (Marschall 1989 : 78).

\section{La poule industrieuse}

Poules et coqs font partie intégrante d'un discours didactique adressé à la jeunesse huppée susceptible d'avoir un jour à collecter des fermages, et habituée à passer ses vacances dans les résidences campagnardes de leurs oncles ou grands-parents de province, où ils s'amusent avec les volatiles, poules, oies ou canards ${ }^{124}$. Ces amusements ne vont pas sans les fondamentaux d'un enseignement avicole. Dans Le Tour de la France par deux enfants, livre de lecture ayant pour objectif la «connaissance de la patrie » enseignée aux plus jeunes à travers la géographie du terroir (Lacassin 1994 : 794), les volailles de Normandie sont à l'honneur: ainsi le "coq de Crèvecœur", dit «magnifique », a-t-il des poules « excellentes pour l'engraissement, un peu moins bonnes pour la ponte. Cette espèce fournit les plus belles et les plus fines volailles des marchés de Paris » ${ }^{125}$

41 L'économie de la poule est enseignée, par le texte comme par l'image, non seulement dans la littérature scolaire, mais aussi dans la bande dessinée. Après-guerre, les bons bourgeois et la petite noblesse - horizon d'attente des lectrices de La Semaine de Suzette dans les années 1920 - font, pour subsister, un retour à la ferme et vont jusqu'à adopter un mode de vie rural. Ainsi Monsieur de Roquefellen s'intéresse-t-il au vignoble et son épouse à la basse-cour pour compléter leurs revenus ${ }^{126}$. Remarquable est le souci constant d'informer la jeunesse des bienfaits de l'élevage des gallinacés, ce, dès la plus tendre enfance. Le Journal de Bébé énumère ainsi les trésors que recèle la poule : pour la cuisine, des œufs, des omelettes et du poulet rôti, pour le confort, le coq réveille-matin, pour la vie militaire, les plumes de coq du plumet des saint-cyriens, horizon d'attente des parents ${ }^{127}$. Les enfants sont instruits des différentes races de poules : la Bantam ${ }^{128}$, la Longhorn, l'Orpington, qui donne «Les plus beaux œufs du monde » ${ }^{129}$, la Wyandotte, la Plymouth Rock, la Leghorn blanche ${ }^{130}$, la Rhode Island ${ }^{131}$ ou la Marans, si bonne pondeuse qu'on la surnomme la poule aux œufs d'or ${ }^{132}$. Aujourd'hui, c'est plutôt la passion pour le patrimoine alimentaire et pour les nourritures du terroir qui pousse les auteurs de BD à préciser, à destination d'un lectorat adulte, la race de la volaille: poule noire de Barbezieux, croquée par Glen Baxter ${ }^{133}$, Coucou du Berry ${ }^{134}$ ou poulet du Guangdong, mitonné par Shinji Saijo dans un manga culinaire ${ }^{135}$.

Parce que toute littérature de jeunesse relève de l'advice litterature, dans la BD, même humoristique, les enfants peuvent apprendre la durée de la couvaison ${ }^{136}$, découvrir de quoi on engraisse les poulets : du maïs ${ }^{137}$ et observer l'étable et la basse-cour. Ces motifs, loin d'être jugés indignes de leur état social, sont au contraire dignes d'intérêt aux yeux des pédagogues ${ }^{138}$ soucieux d'inculquer quelques savoirs de base sur l'élevage, la

Revue d'ethnoécologie, 12 | 2017 
géographie et l'histoire alimentaires de la France ${ }^{139}$ - dont la mythique poule au pot du bon roi Henri IV fait figure d'image identitaire ${ }^{140}$. On retrouve ce type de discours, qui n'est pas réservé aux gallinacés et vaut aussi pour l'alimentation en général (AlexandreBidon 2013), jusque dans les années 1960-1970, par exemple dans Pilote, avec un Pilotorama consacré à «La ferme modèle » dont le poulailler montre des poules élevées en plein air, ou encore dans Spirou avec une "Ferme" qui ne le cède en rien aux panneaux didactiques longtemps accrochés aux murs des écoles primaires ${ }^{141}$. Très tôt, les humoristes parodient ce didactisme un peu lourd. Le dessinateur Henri Avelot, dans ses "Nouveaux tableaux d'école. Leçons de choses ", explique que les poules sont mauvaises laitières (puisqu'elles donnent du lait : le « lait de poule »!) ${ }^{142}$.

La productivité de la ponte et l'engraissement sont aussi des thèmes courants dans la BD même et surtout humoristique, où des inventeurs ingénieurs agronomes rivalisent d'imagination. L'un d'eux crée la poule à deux têtes : pendant que «l'une des deux têtes est occupée à picorer le grain, l'autre tête pond les œufs et réciproquement $»^{143}$. Répondant au titre d'un livre très diffusé dans la France des années 1930, «Poules qui pondent, poules qui paient » (Charon 1929), la devise « There was money in eggs », suscite des gags qui entraînent de gigantesques bris d'œufs pour qui la prend au pied de la lettre ${ }^{144}$. Ce souci de productivité et surtout d'enrichissement ${ }^{145}$ grâce à l'élevage avicole est perceptible dès le premier quart du $\mathrm{xx}^{\mathrm{e}}$ siècle dans la littérature illustrée enfantine. Les magazines pour la jeunesse ne sont évidemment pas les seuls à porter un intérêt passionné à l'aviculture. Dans tous les journaux, à la même date, l'élevage des poules fait l'objet d'articles (Maumené 1933) ${ }^{146}$. Dans les décennies 1920 et surtout 1930, qui reflètent jusque dans la BD une attention encore inégalée pour les gallinacés, collant à la réalité socio-économique, les journaux de l'enfance s'enrichissent de rubriques didactiques sur l'élevage des volailles aux États-Unis, en France, voire dans les pays exotiques ${ }^{147}$. Cet intérêt caractérise une société non encore habituée à l'abondance et surtout traumatisée par les rationnements alimentaires.

De fait, l'aviculture se fait très présente pendant les guerres. La poule tient une place importante dans l'économie de l'arrière, et les magazines illustrés pour la jeunesse s'en font l'écho. Dans la France de 1941, les fillettes croquées par Pinchon, inoubliable créateur de Bécassine, sont éclatantes de santé et de joie dans la cour d'une ferme où, suivies par poules et coq, elles nourrissent les animaux ${ }^{148}$. En Italie, les héros de BD quittent la ville pour aller pratiquer la "pollicoltura» afin de nourrir leur famille ${ }^{149}$. La campagne fait alors pour les enfants figure de pays de cocagne. Le rêve du retour de l'abondance alimentaire se lit dans les aventures du professeur Azimut qui, en 1943, invente "des croissants semblables à des poulets et une brioche qui sautillait dans le poulailler »!150 Les journaux illustrés sous influence pétainiste publiés pendant l'Occupation traitent ces sujets de manière humoristique, en prônant une électroculture (récemment remise au goût du jour par l'agrobioécologie) susceptible de faire pousser légumes et volailles géants (Figure 11). Le grand dessinateur Alain Saint-Ogan, donnant une leçon de civisme sous couvert d'humour, souligne non seulement que les œufs font d'excellentes protéines de substitution, mais encore que la poule, en pleine ère de rationnement, se refuse à pondre si le consommateur n'apporte pas son emballage ${ }^{151}$. 
Figure 11 : Évelyne Pons, « Ca ne pousse pas mal. Ou L'électroculture à outrance vue par Myl et Pat ». Siroco 1941-1943

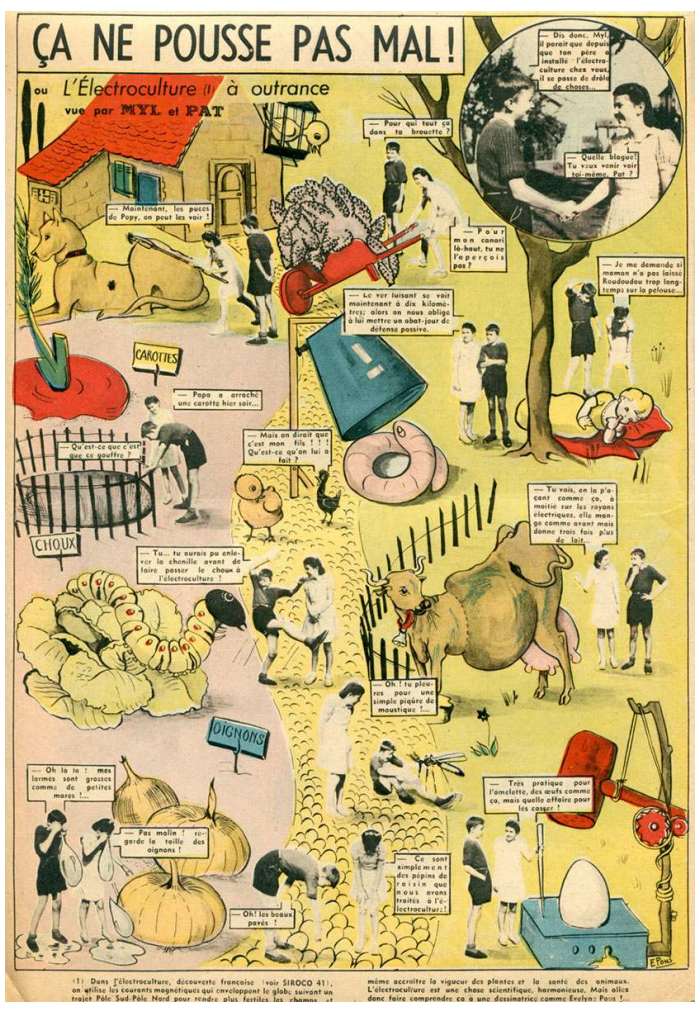

(c) Ancienne collection Pierre Couperie

Après-guerre, les séquelles économiques des conflits se lisent jusque dans les abreuvoirs des poules, et les enfants n'en doivent rien ignorer : « Pour nourrir les volailles. C'était un problème plutôt simple avant la guerre. Mais, maintenant, étant donné le haut prix atteint par les graines et les tourteaux [...] l'engraissement des poules et autres volatiles de basse-cour est devenu un travail plutôt compliqué. ». ${ }^{152}$ En 1946, en France, le paysan écoute à la radio le bulletin agricole et apprend ainsi que les volailles sont en hausse et que "les œufs sont rares et chers " "153; à la même date, aux USA, les citadins encore sous le coup de privations alimentaires vont plus que jamais rendre visite à leurs parents fermiers et éleveurs de poules pour faire le plein de provisions ${ }^{154}$ : «Back to the land of butter and eggs! ${ }^{155}$. Les avantages de l'aviculture sont expliqués aux enfants (Daniels 1971, cahier couleur) ${ }^{156}$ comme aux adultes (Mc Donald 1947), par le biais de l'autobiographie comme de la fiction. L'hyper-productivité alors de rigueur invite à préconiser avec un humour décomplexé - deux ans à peine après Hiroshima ! - la magie des rayons atomiques pour obtenir des poules pondant des œufs blindés ${ }^{157} \ldots$ Au tout début des années 1950, en effet, il est encore de mise de parler aux enfants des applications pacifiques de la radioactivité (Cultru 2006: 82) et d'envisager des accélérateurs de croissance chimiques pour les poules qui grandissent d'un coup et pondent ${ }^{158}$ jusqu'à dix œufs par jour. Mais vingt ans plus tard, lorsque Mandrake enquête sur une mystérieuse disparition survenue dans un élevage de poulets, le voisin suspecté se défend d'être « un savant atomiste. [...] Je travaille sur les ondes ultra-courtes ${ }^{159}$. 


\section{La poule industrielle}

46 Ce véritable phénomène de société qu'est l'intérêt pour l'élevage avicole se reflète largement dans la BD. Les jeunes Américains, fascinés par les couveuses à œufs, imaginent de se substituer aux gallinacés pour la couvaison, mais sur un fauteuil de l'élégant salon de leur mère, à la grande colère de celle-ci (Buster Brown 1976 : 28). Dans la BD des années 1920-1930, la viande, tout autant voire plus que les œufs, devient la cible des consommateurs. ${ }^{160}$ Aux USA, des restaurants spécialisés sont ouverts, permettant ainsi à Annie, la petite orpheline, d'aller souper avec son père adoptif dans un «Chicken Dinner » 161.

47 La rentabilité et la rationalisation de l'élevage font rêver le tout jeune Bicot, héritier d'une famille bourgeoise : quel serait donc le gain si 24 poules pondaient par douzaine ? ${ }^{162}$ Les magazines illustrés ont la réponse à cette question. Dans leurs rubriques didactiques, ils proposent aux jeunes lecteurs des séries de chiffres propres à enflammer leur imagination. On leur apprend donc que les poulaillers à grande échelle de Brampton produisent 225000 œufs par an couvés par 33000 poules couveuses !163 Plus fort encore, que les poules sont si rares en Bulgarie qu'il faut à ce pays importer quelque 12 millions de kilos d'œufs par le train ${ }^{164}$. Plus étonnant, qu'un palace de Floride abandonné a été transformé en poulailler géant et abrite pas moins de 110000 poules, 89000 poulets et 65000 pigeons ! ${ }^{165}$ En 1958, le journal Spirou met en évidence une courbe de croissance impressionnante : «Grâce à une meilleure alimentation des bêtes, à des croisements plus judicieux, et à une organisation plus avisée [...] alors qu'en 1934, le nombre des poulets de grain produits dans l'année avait été de 34 millions, c'est environ 1500 millions de volatiles qu'élèvent maintenant tous les ans les aviculteurs américains. En outre, la production des œufs a augmenté de $45 \%$ par poule $»^{166}$. De tels appels de chiffres existent encore dans les années 1990, mais ils n'ont plus valeur de modèle : les nombres, devenus inconcevables pour l'esprit d'un enfant, ne sont plus qu'un jeu mathématique : «Il y a 9,661 milliards de poules dans le monde, qui pondent annuellement 34,939 millions de tonnes d'œufs » ${ }^{167}$. Les scénaristes d'une BD parodique dont les héros sont des gallinacés peuvent donc afficher «un lectorat potentiel de dix milliards de poules sur cette planète... $»^{168}$.

Dès les années 1930, en matière d'aviculture, produire plus pour gagner plus est devenu le maître mot. Les enfants terribles de la BD engraissent les poules de maïs à popcorn pour les faire enfler plus vite, tels les Katzenjammer Kids en couverture du comic book éponyme ${ }^{169}$. Des éleveurs sont les héros d'une sordide histoire policière dont les protagonistes « se disputaient toujours à propos de la meilleure nourriture à donner aux poulets ", lit-on dans une aventure de Mandrake ${ }^{170} \ldots$ La bulle avicole ne se dégonfle pas. Dans les années 1950, les comic books témoignent directement des pratiques d'élevage de leur temps en évoquant les concours de coqs et de poules visités par les classes primaires, les "poultry election " à succès ${ }^{171}$. Ils sacrent la Leghorn "Miss American Hen ${ }^{172}$. Le poulet est en train de devenir une viande quotidienne et, pour répondre à la demande croissante, l'élevage industriel a été vu comme un progrès dont les enfants ont été instruits par l'intermédiaire de jouets, notamment aux États-Unis où le colonel Sanders est décliné sous la forme d'un personnage publicitaire à destination des jeunes amateurs de Kentucky Fried Chickens ${ }^{173}$. Dans l'immédiat après-guerre encore soumis aux pénuries et au rationnement, nul n'est choqué à la lecture d'une brève illustrée sur l'invention de la poule sans ailes ${ }^{174}$ (Figure 12), les ailes étant alors considérées comme un déchet. 
Figure 12 : «Des poules sans ailes », rubrique « C'est curieux mais vrai », Bravo, $9^{e}$ année, $n^{\circ} 38,22$ septembre 1949

DES POULES SANS AILES...

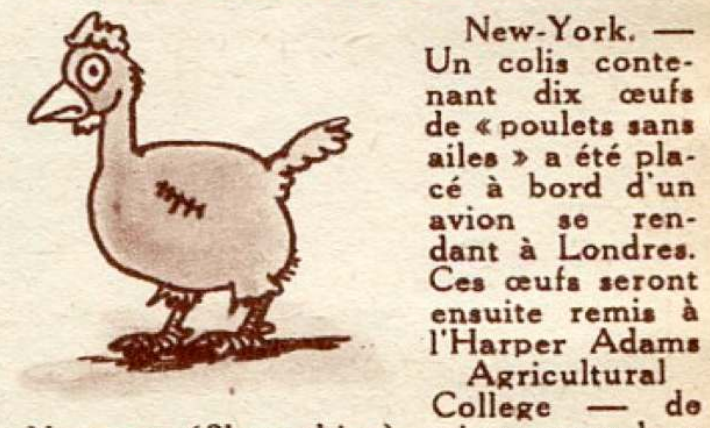

Newport (Shropshire) qui assurera leur incubation,

Ces «poulets sans ailes s sont le fruit de douze ans de recherches et de 15.000 dollars de dépense, effectuées par un fermier de l'lowa qui a ainsi réuesi à produire une race de gallimacés plus riche en viande du fait de l'absence de la structure osseuse des ailes.

Les dix ceufs qui ont été envoyés en Angleterre ont été achetés par le journal londonien « Daily Express 》 qui désire \& apporter sa contribution à la solution de la pénurie de viande dont souffre la Grande-Bretagne \$.

(c) Ancienne collection Pierre Couperie

\section{La vengeance des poulets}

En France, dès les années 1950, l'élevage avicole a joué la carte de la BD pour sa publicité. La marque Duquesne-Purina a ainsi commandé à Pesch «Les aventures de Poussinet " (Derouet 2011 : 158-160) et le même auteur a ultérieurement composé une "Loué story " mettant à l'honneur ses volailles « fermières » de la société éponyme. Aux États-Unis, la publicité pour le fast-food, et notamment le poulet, a opté pour une expression sous forme de BD dès les années $1960^{175}$. Mais en aucun cas les comics, publicitaires ou de fiction, n'ont fait allusion aux horreurs de l'abattage de masse, ni au rôle de cobaye joué à leur corps défendant par les poulets. Il faut attendre les années 1970 pour que soient dénoncés l'élevage en batterie et le martyre des gallinacés. La transformation des malheureux volatiles en nuggets dans un contexte d'alimentation de masse n'a pas laissé indifférent l'underground américain. Dès 1970, Gilbert Shelton, l'un des plus connus des dessinateurs de comix, a mis en scène, à Atlanta, des poulets géants occupés à dévorer les entrailles du Colonel Sanders, sur un arrière-plan d'usine de fabrication des célèbres Southern Frieds Chickens (Estren 1974 : 147). Un comic book imagine que les hommes, ayant souffert de radiations, voient leur taille réduite, contrairement aux poulets devenus géants et prêts à les gober tout crus ${ }^{176}$. Juste vengeance !

En France aussi, la prise de conscience date du début des années 1970. Le premier journal de BD à avoir réagi à l'élevage en batterie est Pilote. En 1971, dans une série réaliste consacrée à « la longue empoignade de l'homme et de la terre nourricière ${ }^{177}$, le journal dénonce l'automatisme dans l'agriculture et l'élevage : «[...] la poule pondeuse moderne 
naît dans une boîte où elle passera toute sa vie, sans jamais voir le jour. Elle pond des œufs calibrés à l'avance, à longueur d'années, qui sont empaquetés, contrôlés puis distribués sans que le "fermier » (qui est un technicien) n'ait eu à s'en occuper ». À cette même date est (discrètement!) combattu le poulet aux hormones ${ }^{178}$, et dénoncé, sous couvert d'humour, l'élevage en batterie dans des «entreprises avicoles» qualifiées $\mathrm{d}^{\prime}$ " usines de poules $\aleph^{179}$. Le modèle du poulailler industriel fait dès lors figure de repoussoir : « éclairé comme si le soleil se levait et se couchait deux fois par jour ; comme les poules pondent au lever du soleil, ce système les fait pondre deux fois plus, mais il les fatigue deux fois plus aussi !!! $\aleph^{180}$. La poule industrielle devient la métaphore du malvivre. Mais il faut attendre les années 1990-2000 pour que l'horreur des abattoirs de volailles soit dénoncée par plusieurs auteurs ${ }^{181}$ : une bien lente prise de conscience du sort de celles qui furent les cobayes de l'industrie alimentaire. Presque rien ne transparait des pratiques d'abattage, ni de la conscience humaine confrontée au travail avicole, sujet abordé dans un mince volume de $\mathrm{BD}$ au titre programmatique: Cot Cot, et dont l'onomatopée, obsédante, constitue aussi le seul texte ${ }^{182}$.

51 On pourrait en conclure que le sort des poulets importe moins que le contenu des estomacs. Pourtant, le combat contre la «malbouffe » est aussi un phénomène récent. Il faut attendre les toutes dernières années pour assister à une dénonciation des produits de l'élevage de masse servis dans les restaurants, assortie de dialogues épicés: «-Votre poulet basquaise, il est comment? - C'est une pauvre cuisse de poulet en batterie qu'on fait frire dans de l'huile de récup. [... servi] dans une sauce industrielle. $»^{183}$. La nature de l'élevage, la question des farines animales dans l'alimentation des volailles et la médiocre qualité du poulet frit servi dans les fast-foods selon la recette inventée par « The Colonel of two Worlds $»^{184}$ sont désormais pointées du doigt.

Dans la BD, la prise de conscience est tout aussi lente chez les poules françaises. Il faut attendre les années 2000 pour qu'elles se rebellent ${ }^{185}$, pour que chicken nuggets devienne une injure ${ }^{186}$, et les années 2010 pour que la BD alerte sur la grippe aviaire ${ }^{187}$ et pour que soit dénoncé le poulet «industriel »" Dorénavant, même les poules domestiques se révoltent ${ }^{189}$, font la grève de la ponte, exigent de meilleures conditions de vie et de travail, et voient naître en elles une conscience sociale : «Je vis sans coq et cloitrée par un homme sans pitié qui fait de moi un simple animal de compagnie. Tous les jours je ponds un œuf infécondé, moi qui rêvais de fonder une famille $»^{190} \ldots$ En dépit d'utopies où hommes et poules vivent en bonne intelligence, sous le même toit, dans des maisonspoulaillers (Harringer \& Baron-Carvais 1992: 23), et d'images surréalistes où les meubles les plus design servent de nids aux poules, tel le célèbre fauteuil de Rietveld ${ }^{191}$, le sort des gallinacés, vu du côté des poulets, reste sombre et douloureux.

Si l'élevage industriel a temporairement écarté les enfants des gallinacés au point qu'ils ne les reconnaissent plus qu'une fois emballés sous plastique, comme dans un gag des Triplés (Figure 13), et qu'ils ne veulent pas admettre que les œufs, «ça sortait des fesses des poules » et non d'un rayon du supermarché ${ }^{192}$, le retour actuel au pavillon individuel avec jardin et poulailler a réactivé le rapport qu'entretiennent les jeunes lecteurs - et les dessinateurs - aux gallinacés. Depuis les années 2000, la poule est redevenue un animal familier. Elle symbolise le home sweet home des bobos faisant un retour à la terre ${ }^{193}$. La BD se fait l'écho d'une écologie qui inclut la consommation d'œufs bio si possible produits à domicile par des semi-urbains ignorants tout de l'élevage avicole, mais qui ne manquent pas de s'informer en achetant des livres spécialisés dont les titres sont méchamment parodiés: "La Constipation chez les poules", "Les Poules face aux intempéries", 
"Soignez vos poules », "Les Poules insomniaques ", «Les Mouvements de libération des poules », «La Poule analysée », par Froïd, etc. ${ }^{194}$. La poule de papier a finalement réussi à conquérir sa place dans le domaine éditorial : en 2005, une maison d'édition de BD n'hésite pas à se baptiser « Poulailler Production » avec pour héros un petit œuf ${ }^{195}$ et une ponte régulière: huit albums en dix ans, et même un livre de recettes en $\mathrm{BD}$... Aujourd'hui, écologie oblige, les cocottes en plume et en papier sont à la mode. Un peu de douceur dans un monde de brutes ? La poule est (peut-être) l'avenir de l'homme...

Figure 13 : Nicole Lambert, Les Triplés, Trois amis des bêtes, Paris, Hachette, 1991

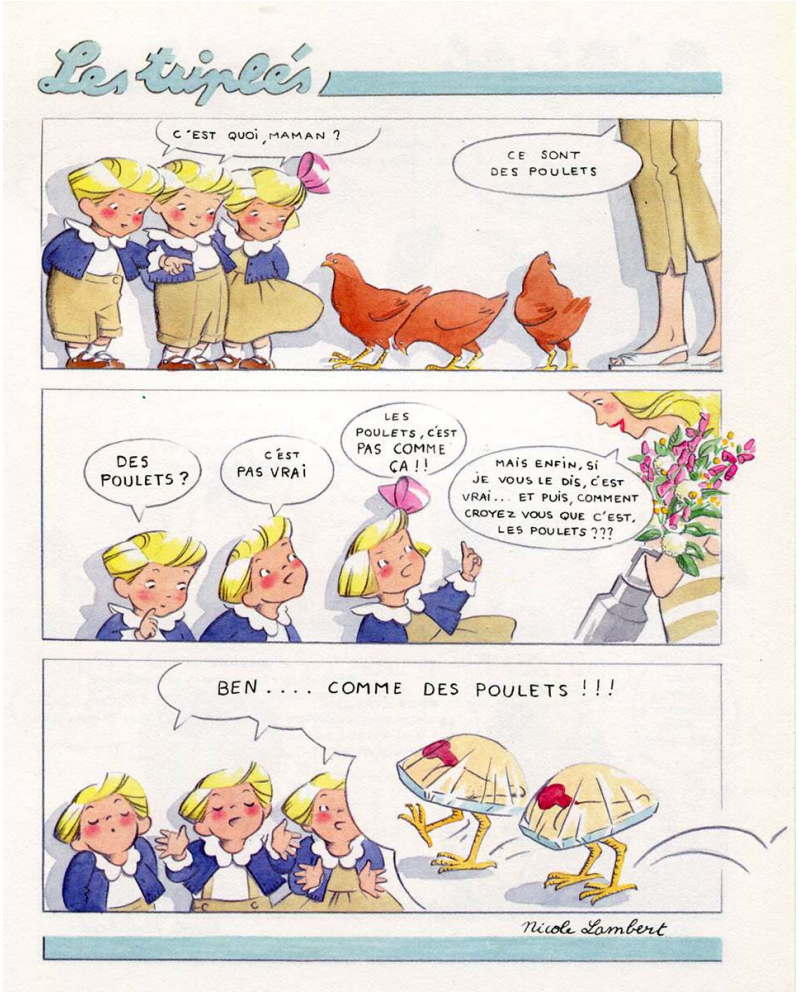

Avec l'aimable autorisation de l'auteur

\section{BIBLIOGRAPHIE}

Alexandre-Bidon D. 2013 - Les nourritures du terroir dans les illustrés pour la famille et l'enfance (1900-2010). In : Andrieux J.-Y. \& Harismendy P. (Ed.), L'Assiette du touriste : le goût de l'authentique, Actes du colloque international organisé à Saint-Brieuc les 6 et 7 juin 2012. Rennes, Presses universitaires de Rennes/Tours, Presses universitaires François-Rabelais de Tours : 233-254.

(Tables des hommes).

Alexandre-Bidon D. 2017 - Des histoires en cul-de-poule. Club Sandwich Magazine 1, L'Euf, mars : 75-77. 
Arts incompris 1887 - Exposition incohérente des Arts incompris. Catalogue de l'exposition organisée par la Société Gallinophile La Poularde, $2^{e}$ année. Bourg, Imprimerie Villefranche, n.p.

Benjamin Rabier 1981 - Benjamin Rabier. Catalogue de l'exposition. Paris, musée Galerie de la Seita, n.p.

Benjamin Rabier 1982 - Benjamin Rabier. Présentation d'É. François, choix de P. Couperie. Paris, Pierre Horay, n.p.

Bettley J. (Ed.) 2001 - The Art of the Book from Medieval Manuscript to Graphic Novel. Londres, V\&A Publications, 208 p.

Betty Boop 1975 - Betty Boop by Max Fleischer. New York, Flare Books/Avon, n.p.

Blackbeard B. \& Williams M. (Ed.) 1977 - The Smithsonian Collection of Newspaper Comics. New York, SIP \& Harry N. Abrams Inc., 336 p.

Buster Brown 1976 - Buster Brown. Paris, Pierre Horay, 124 p.

Canemaker J. 2005 - Winsor McCay. His Life and Art. (Éd. revise). New York, Harry N. Abrams, 272 p.

Charon A.-J. 1929 - Poules qui pondent, poules qui paient. Méthodes d'aviculture anglo-américaines.

Paris, Librairie agricole de la « Maison rustique », 264 p.

Coq Hardi s.d. - Dossier Coq Hardi. Haga, Revue de la Bande Dessinée 20-21, 84-16 p.

Coq Hardi 1981 - Les prémisses de Coq hardi. 1939-1944. In : Coq Hardi, n 1 à 10, 1944-1945. Rééd.

Paris, Les Éditions de Chateaudun, n.p. : 6 p.

Corriere 1979 - Il Meglio del Corriere dei Piccoli. 1, 1908-1920. Milan, Rizzoli, 366 p.

Couderc M.-A. 2005 - La Semaine de Suzette. Histoires de filles. Paris, CNRS Éditions, 256 p.

Couperie P. 1997 - Autour du mouvement bédéphile. Entretien avec Pierre Couperie. In : Gaillard N. (textes réunis par), La Bande dessinée. Histoire, développement, signification. Numéro spécial de Contre-champ $1: 131-146$.

Cultru H. 2006 - Vaillant, le journal le plus captivant. 1942-1969 : la véritable histoire d'un journal mythique. Paris, Vaillant collector, $285 \mathrm{p}$.

Daniels L. 1971 - Comix. A History of Comic Books in America. New York, Outerbridge \& Dienstfrey, $198 \mathrm{p}$.

Denoyelle 2014 - Le Roman de Renart en bandes dessinées : des ambiguïtés de l'anthropomorphisme animalier. In : Reusse-Elzingre A. \& Corbellari A., Le Moyen Âge en bulles. Gollion, Infolio : 165-180.

Derouet J. 2011 - Jean-Louis Pesch et ses héros de papier. Turquant, L'apart Éditions, 242 p.

Estren M.J. 1974 - A History of Underground Comics. New York, Straight Arrow Books, 320 p.

George McManus 1977 - George McManus, Bringing up Father. A Complete Compilation: 1913-1914.

Westport, Hyperion Press, 166 p.

Gifford D. 1976 - Victorian Comics. Londres, George Allen \& Unwin Ltd, Ruskin House, 144 p.

Goddin P. 1984 - Corentin et les chemins du merveilleux. Paul Cuvelier et la bande dessinée. Bruxelles, Éditions du Lombard, 120 p.

Gris P. 2014 - Gerry Alanguilan : des poulets et des hommes, Bodoï [En ligne], http:// www.bodoi.info/gerry-alanguilan-des-poulets-et-des-hommes/ Consulté le 12 février 2017. 
Groensteen T. (Ed.) 1987 - Une histoire critique de la bande dessinée animalière. Animaux en cases. Paris, Futuropolis, 222 p.

Groensteen T. (Ed.) 2000 - Maîtres de la bande dessinée européenne. Catalogue de l'exposition. Paris, BnF/Le Seuil, 207 p.

Guichet J.-L. 2006 - Rousseau, l'animal et l'homme. Paris, Le Cerf, 464 p.

Harai D. 2006 - Poule sacrée, poule profane : divination et comédie dans un pamphlet de la guerre de Piémont (1600). Italies. https://italies.revues.org/1122 Consulté le 9 février 2017.

Harringer C. \& Baron-Carvais A. (Ed.) 1992 - « Kein Schöner Land... »/La Revanche des régions. Grenoble-Paris-Düsseldorf, Glénat Concept/Institut Goethe/Institut français, 57-67 p.

House S. 1982 - The Dictionary of British Book Illustrators and Caricaturists, 1800-1914. Farmington Hills, The Gale Group, 520 p.

Inside Collector 1993 - The Inside Collector 3 (9), juillet-août.

Lacassin F. (présenté par) 1994 - Des enfants sur les routes. Paris, Laffont, 1153 p.

Loetscher H. 1984 - Le Coq prêcheur. De l'utilisation littéraire et morale des animaux. Paris, Fayard, $336 \mathrm{p}$.

Mc Donald B. 1947 - L'E Euf et moi. Paris, Le Livre de poche/Robert Laffont, 277 p.

McManus 1977 - George McManus, Bringing up Father, A Complete Compilation: 1913-1914. Westport, Hyperion Press, 166 p.

Marcolini P. 2016 - La propagande contre elle-même. « La ferme des animaux » en bande dessinée. In : La Ferme des animaux, d'après George Orwell. Paris, L'Échappée, n.p. : 14 p.

Marschall R. 1987 - Snappy Art, Sappy Copy. The Comic Strip Ads of Milton Caniff and Noel Sickles. Nemo. The Classic Comics Library 25 : 36-46.

Marschall R. 1989 - America's Great Comic-Strip Artists. New York, Abbeville Press, 295 p.

Marschall R. 1997 - Rudolph Dirks. Le Collectionneur de bandes dessinées 82, printemps 1997 : 11-19.

Maumené B.A. 1933 - Les revenus possibles d'une propriété d'agrément. Le Figaro illustré, juilletaoût.

Moliterni C. (Ed.) 1980 - Histoire mondiale de la Bande dessinée. Paris, Pierre Horay, 252 p.

Morgan H. 2000 - Animaux en crise. In : Groensteen T., Maîtres de la bande dessinée européenne. Catalogue de l'exposition, Paris, BnF/Le Seuil : 94-103.

Orwell G. (1945) 1970 - Animal Farm. A Fairy Story. Londres, Penguin Book, 119 p.

La Presse 2017 - La Presse à la une, de la Gazette à l'internet. Paris, BnF. [En ligne] http:// expositions.bnf.fr/presse/index.htm. Consulté le 12 mars 2017.

Robichon F. 1984 - Job ou L'Histoire illustrée. Paris, Herscher, 224 p.

Wilhelm Busch 1966 - Das Grosse Wilhelm Busch Hausbuch, Ein heiteres Album mit einer Würdigung von Dr Curt Elwenspoek. Munich, Südwest Verlag, 624 p.

Winsor McCay 1977 - Winsor McCay's Dream Days. An Original Compilation 1904-1914. New York, The Hyperion Library of Classic American Comic Strip, 178 p. 


\section{NOTES}

1. Cour d'appel de Riom, $1^{\text {re }}$ chambre civile, arrêt du 7 septembre 1995.

2. Couverture de Le Petit Français illustré. Journal des écoliers et des écolières, 30 juin 1900.

3. Querelle d'Écossais et vol de poules dans Illustrated Chips, n 509, 2 juin 1900. Voir Gifford 1976, 25 ; Betty Boop 1975 (1935-1936).

4. Ally Sloper's Half Holiday, vol. II, $\mathrm{n}^{\circ}$ 57, 30 mai 1885.

5. Kid, « Babylas et son réveil original », Pierrot, $n^{\circ} 19,21$ septembre 1947.

6. Tabary, «Valentin le vagabond et les hippies », Pilote, $\mathrm{n}^{\circ} 712,28$ juin 1973.

7. Wallis et De Groot, « Chlorophylle », Tintin, 38e année, $n^{\circ}$ 51, n 432, 20 décembre 1983.

8. M. Le Normand, «Le plus fier de tous », Le Journal de Mickey, n 1738, octobre 1985.

9. S. Martin et C. Ngalle Edimo, Marcel et Léa, Paris, Fnac, 2003.

10. P. Sullivan, Félix et Zizi, Paris, Hachette, 1939.

11. Falco, «Le réveil à la ferme », La Jeunesse illustrée, 1934, couverture de l'album relié.

12. Entre cent autres exemples : Sto (S. Tofano), Bonaventura, Corriere dei Piccoli, $n^{\circ} 13,25$ mars 1928 ; G. Arriola, « Gordo », The Sunday Denver Post, $1^{\mathrm{er}}$ octobre 1972.

13. Martial, Tutti frutti, «L'horloge astronomique », Nouveau Tintin, $\mathrm{n}^{\circ} 69$ (209), 4 janvier 1977 ;

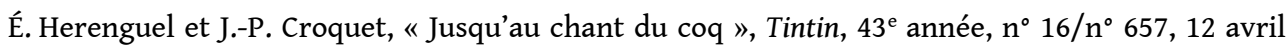
1988.

14. R. Rigot et A. Richomme, Jeanne d'Arc, Paris, Fleurus, 1950.

15. M. Caniff, « Peter joins the Club. An Advertisement for Postum », 1936. Publicité pour du café.

16. B. Rabier, Jeannot-Lapin et Cie, Paris, Tallandier, 1913. Voir Benjamin Rabier 1982.

17. Spirou, $18^{\mathrm{e}}$ année, $\mathrm{n}^{\circ} 874,13$ janvier 1955.

18. Gonzague-Privat, «L'équipage de la Rosette », Le Journal de la jeunesse, $n^{\circ} 1375,8$ avril 1899; Ymer, « Le filleul du cousin Properce », La Jeunesse illustrée, 28e année, $n^{\circ} 1372,19$ janvier 1930.

19. Bill Holman «Smokey Stover»; dessin humoristique de Vasquez, 1971, publié dans Xanadu, novembre 1971.

20. C. Gourville, «Le dévouement de Simonne », Le Journal rose, magazine illustré des fillettes, $\mathrm{n}^{\circ} 97$, 13 août 1913.

21. P. Christin et A. Goetzinger, La Voyageuse de la petite ceinture, Neuilly-sur-Seine, Dargaud, 1985.

22. J. Northcote RA (1746-1831), illustration pour One Hundred Fables, 1878, gravure sur bois. Extrait de House 1982, 403.

23. Ymer, « La maison des Julien », La Jeunesse illustrée, 29e année, $\mathrm{n}^{\circ} 1425,25$ janvier 1931.

24. Une "vieille fermière ridée qui vient de récolter les œufs de ses poules", un "fermier conduisant une brouette remplie d'œufs ». Pouf, « Cadeaux amusants », Almanach de Guignol 1936. 25. Steinlein, «La bergère et le loup ", Imagerie humoristique et enfantine, série $4, n^{\circ} 3$, Paris, Imprimerie-Librairie Quantin, 1897. Lausanne, musée cantonal des Beaux-Arts.

26. Jinpachi Mori et Hideaki Hataji, Les Fils de la terre, t. 1, Paris, Delcourt, 2007.

27. Silas (Winsor McCay), « Dream of the Rarebit Fiend », 4 août 1907.

28. Zap Comix, 1968 ; Insect Fear, 1969 ; Dan O'Neil's Comics, 1971.

29. M. Konture, « Les Kontures », Lapin, $n^{\circ}$ 14, janvier 1997.

30. L. Knicksley, Délices. Ma vie en cuisine, Paris, Delcourt, 2014.

31. J. Jeannet, « Colette la peureuse », Lisette, $13^{\mathrm{e}}$ année, $\mathrm{n}^{\circ} 22,28$ mai 1933.

32. Un coq dispute sa bouillie à un tout petit garçon dans le hors texte couleur de Little Folks. A Magazine for the Young, Londres, Cassell and Company, 1898.

33. R. de la Nézière, Le Petit Buffon illustré, Paris, Hachette, 1928.

34. Voir Corriere 1979, 284.

35. L. Lajarrige, « Sur le coq du clocher », Le Jeudi de la jeunesse, 4e année, n 161, 13 juin 1907. 
36. P. Sullivan, Félix et Furioso, Paris, Hachette, 1939.

37. B. Rabier, «Ingéniosité maternelle »; "La bonne poule », Id., Les Animaux s'amusent, Paris, Librairie Garnier Frères, 1923. Voir Benjamin Rabier 1982.

38. W. Disney, «Silly Symphony ", d'après le dessin animé « The Wise Little Hen », 16 septembre 1934 ; parution en France sous le titre « La petite poule avisée ", $1^{\text {er }}$ épisode : Le Journal de Mickey, $2^{\mathrm{e}}$ année, $\mathrm{n}^{\circ} 28,28$ avril 1935.

39. Marijac, «Lyne et Zoum », Wrill, $1^{\text {re }}$ année, $n^{\circ} 22,1946$.

40. Illustration de l'appel aux auteurs de textes dans Little Folks. A Magazine for the Young, Londres, Cassell and Company, 1898, 216.

41. Sto, «Felicetta e Feliccino son sorella e fratellino, e con lor la gallinella che Felicita s'appella ", Novara, Istituto Geographico De Agostini, 1946 ; Micheline, " Ma poulette blanche », récit illustré, Fillette, n 1755, 8 mars 1942 ; Jo. Valle, « Trompette ", Cri-Cri, $18^{\mathrm{e}}$ année, $\mathrm{n}^{\circ}$ 870, 30 mai 1935.

42. Franquin et Jidéhem, Gaston R3, Gare aux gaffes du gars gonflé, Marcinelle-Charleroi, Dupuis, 1973.

43. Delporte, Jidéhem et Franquin (concepteur), Les Robinsons du rail, Sèvres, Éditions de l'atelier, 1981. Feuilleton paru en 1964 dans le journal Spirou.

44. G. Bess, « La tribu terrible », Tintin, 29e année, n 52, 25 décembre 1973.

45. Un voile pudique doit être jeté sur les abus sexuels dont les poules sont victimes dans Gaudelette et Sauger, Radada la méchante sorcière, Paris, Audie-Fluide Glacial, 2004.

46. Binet et Hausman, Allez coucher sales bêtes, Marcinelle-Charleroi, Dupuis, 1991.

47. Dimitri, La Malvoisine, Bruxelles, PعT Production/Joker Éditions, 2007.

48. "Chicken sexual fantasies », G. Larson, The Chicken are restless, Kansas City, Andrews McMill Publishing, [1993] 1999.

49. Walli et Bom, «Chlorophylle », Tintin, 39e année, $n^{\circ}$ 30/n 463, 24 juillet 1984.

50. B. Rabier, Le Roman de Renart, Paris, Tallandier, 1909 (coq en médaillon sur la couverture) ; «Le Roman de Renard», Frivolet, Le Journal du petit Français, 2 $2^{\mathrm{e}}$ année, n 12, 20 mars 1947 ; J. Trubert, «Le roman de Renart », publié dans Vaillant de novembre 1956-août 1957 ; Goscinny et Uderzo, «Le Roman de Renart ", série destinée à Pilote, abandonnée au profit d'Astérix; Hausman, Le Roman de Renart, 1971, rééd. Marcinelle-Charleroi, Dupuis, 2012 ; J.-C. Forest et Cabanes, «Le Roman de Renart ", A suivre, n 1, février 1978 (en première page, voir le squelette d'une poule...).

51. http://gallica.bnf.fr/ark:/12148/bpt6k65670289. Je remercie Mickaël Wilmart de m'avoir signalé ce titre.

52. M. Barr, Mémoires d'une poule noire, Paris, Paul Ducroq, 1868. Source : Gallica ; Les 400 coups d'un gamin de Paris, Paris, Tallandier, 1933.

53. H. Beney et J. Mariolle, La Petite poule rousse, Charnay-lès-Mâcon, Bamboo, 2014.

54. Cécile Boulaire, rapport d'HDR, "Démarches, théories \& réflexions personnelles", 16 novembre 2014. Je remercie Martine Lamarque de m'avoir communiqué ce texte.

55. La série de C. Jolibois et C. Heinrich comporte d'ailleurs un épisode médiéval : Les P'tites poules, la bête et le chevalier, Paris, Pocket Jeunesse, 2010.

56. J. de Marcillac, «La chasse aux poulets », jeu d'extérieur, Bayard, $3^{\mathrm{e}}$ année, $\mathrm{n}^{\circ} 136,7$ août 1938. 57. «La poule boit ", Bayard, $n^{\circ} 232,4$ décembre 1960 ; le plus célèbre est la machine à faire les œufs carrés de Pif, gadget repris tout récemment : Super Pif, nº 6, décembre 2016.

58. Le texte original, en souabe, indique simplement que ces volailles sont «cuites à la poêle». Cette traduction de Yohann Chanoir, que je remercie pour sa lecture, démontre à quel point il convient de se méfier des adaptations en français, susceptibles de fournir des indicationserronées sur la culture matérielle et les faits de société. 
59. W. Busch, Max et Moritz, adapté de l'allemand par Cavanna, Paris, L'École des loisirs, 1980, ici p. 6-21, et Idem, Max et Maurice ou Les Sept mauvais tours de deux petits garçons, traduit par André Thérive, Paris, Flammarion, 1952.

60. Knerr, The Katzenjammer Kids, Feature Books, n³0, 1937.

61. À la fin des années 1960, la BD comprenait déjà "dix millions d'images ", titre donné par Pierre Couperie à l'une des toutes premières expositions sur le $9^{\mathrm{e}}$ art en France.

62. Entre autres, voir, sur l'éthologie des poules - et des humains - "L'esprit des bêtes ", imagerie Pellerin, série aux armes d'Épinal $n^{\circ} 156$, Histoires et scènes humoristiques, contes moraux ; «Les espiègleries d'Ernest », Pellerin et Cie, imagerie d'Épinal n 577 ; sur le caractère militaire du coq : «Un shako sur deux pattes », Pellerin et Cie, imagerie d'Épinal, n²657, etc.

63. Asy, « La vision du roi Sabalim », Les Belles images, 20 mai 1920.

64. W. Kelly, «The Story of Chicken Little », Uncle Pogo So-So Stories, New York, Simon \& Schuster, 1953 (5 $5^{\mathrm{e}}$ édition).

65. W. McCay, « Little Sammy Sneeze », New York Herald, 1904.

66. La Bande des '89, Histoires d'O[eufs], Paris, Écho Vision Éditions, 1989.

67. Premier épisode : Walt Disney, «La petite poule avisée ", Symphonies folâtres, Le Journal de Mickey, $2^{\mathrm{e}}$ année, $\mathrm{n}^{\circ}$ 28, 28 avril 1935, premier épisode.

68. Rob-Vel, «Les aventures de Toto et de son pompon magique », Le Journal de Toto, $3^{\mathrm{e}}$ année, $\mathrm{n}$ - 139, 2 novembre 1939.

69. W. Disney, Les Aventures de Mickey, Paris, Hachette, 1931.

70. E. Stern, « Die Wahlen in Österreich », Lustige Blätter, $22^{\mathrm{e}}$ année, $\mathrm{n}^{\circ} 25,1907$.

71. Voir la poule et ses poussins de Kurt Schwitters, Der Scheuche Märchen, Hanovre, 1925, reproduite dans Bettley (Ed.) 2001, p. 113.

72. Couverture de Il Balilla, XII ${ }^{\mathrm{e}}$ année, $\mathrm{n}^{\circ} 5,1^{\mathrm{er}}$ février 1934.

73. L. Bottaro, couverture de If, $\mathrm{II}^{\mathrm{e}}$ année, $\mathrm{n}^{\circ} 8$, octobre-décembre 1974.

74. Voir les poulets géants de «The Blasphemy of Fred», Dan O'Neill Comics, vol. 1, n 1, janvier 1948 (sic : en réalité 1971).

75. Cornélius et L. Trondheim, «La poule et La pétanque », dans le fanzine ACCI H3319, Bordeaux, Éditions Cornélius, 1988 ; Ibn Al Rabin, Cot Cot, Genève, Atrabile, 2003.

76. Crisse, «Le coq de Kochi », rubrique « Nahomi présente », Tintin, $40^{e}$ année, $n^{\circ} 17 / n^{\circ} 482,23$ avril 1985.

77. W. Disney, Les Aventures de Mickey, Paris, Hachette, 1931 ; « Mariagrazia mia cugina », I Piccoli della Gazetta, III année, $\mathrm{n}^{\circ}$ 41, octobre 1949.

78. Loisel et Tripp, Magasin général, t. 4, Confessions, 2008 ; idem, 2014 ; procédé repris par Farkas et Tackian, Rédemption, 1, Dévotion, Toulon, Soleil, 2014.

79. J. Van Beer, en couverture de Rires et grimaces, par Forain, Caran d'Ache, Pille, Willette, Godefroy, Guillaume et Fau, n.d. ; voir aussi M. Prangey, « Poull et Kok en voyage », Jeudi, n 307, 12 août 1937.

80. F. Le Gall, dans Spirou, $n^{\circ} 3102,24$ septembre 1997.

81. La Jeunesse moderne amuse et instruit, $2^{\mathrm{e}}$ année, $\mathrm{n}^{\circ} 41,14$ octobre 1905.

82. "L'esprit des bêtes", imagerie Pellerin, série aux armes d'Épinal $n^{\circ} 156$, Histoires et scènes humoristiques, contes moraux, merveilleux.

83. La couverture de L'Écho des savanes, $n^{\circ} 16,1^{\mathrm{er}}$ janvier 1976, montre une figure mixte, mi poule, mi femme, dénudée, de profil, en train de pondre un œuf qu'elle gobe tout de go.

84. Christophe, La Famille Fenouillard, Paris, Armand Colin, [1893] 1960.

85. F. Ricard, «Les beaux dimanches de Godet et Balochot », La Vie de garnison, $13^{\mathrm{e}}$ année, $\mathrm{n}^{\circ} 377$ (nouvelle série n 99), 7 août 1921.

86. W. Disney, «Daisy, reporter sportif», Le Journal de Mickey, n 421, 19 juin 1960 ; Sokal, Canardo, Premières enquêtes, Bruxelles, Pepperland, 1979.

87. E. Sio, « La gallina Catalina », v. 1968. 
88. Hermann, Éloïse de Montgri, Grenoble, Glénat, 1985.

89. Voir dans le même volume l'article de Valérie Boudier.

90. J.-C. Servais, La Belle coquetière, t. 2, Marcinelle-Charleroi, Dupuis, 1997.

91. W. Kelly, « Whose God is dead? », Walt Kelly Unmasked, The Pogo Poop Book, New York, Simon \& Schuster, 1966.

92. É. E. Schmitt et Janry, Les aventures de Poussin $1^{\mathrm{er}}$, t. 1, Cui suis-je ?, 2013.

93. Tarabiscouille, «Jésus ", Turkey, ${ }^{\circ}$ 20, [2011] 2012, p. 174.

94. Voir, dans le même volume, l'article de Marie Anne Polo de Beaulieu.

95. E. Brants, Save me Pythie, Paris-Bruxelles, Éditions Kana, 2014.

96. Georgette de Montenay, Emblemes, ou Devises chrestiennes, Lyon, Jean Marcorelle, 1571. Paris, BnF, Dpt des Livres rares et précieux, RES. P-Z-2659 (1).

97. J.-L. Pesch, Bec-en-Fer chez les Flamands, Paris, Fleurus, 1985.

98. E. Stern, «Die Wahlen in Österrreich », Lustige Blatter, $n^{\circ}$ 25, 1907 : « Les élections en Autriche. Cela dépend si les enfants ont différents parents». Selon Yohann Chanoir, que je remercie pour sa traduction et son explication, la couleur du plumage (rouge pour la gauche, noir pour les conservateurs) renvoie aux partis présentés sous forme de petits poulets face à la poule personnification de l'Autriche.

99. Le coq est en couverture de J. Bainville et Job, Petite histoire de France, Alfred Mame et Fils, [1928] 1930.

100. Job, « La République de 1848 », Les Trois couleurs. Image publiée dans Robichon 1984.

101. Couverture de Dubout pour Satirix, $n^{\circ} 18$, mars 1973.

102. Dessin de B. Rabier, 1915. Paris, BnF, TF-1304-FOL.Voir l'article de Michel Pastoureau.

103. Voir par exemple B. Rabier, « Cocorico!» dessin aquarellé au pochoir, 1915 ; Id., «Rentrée d'Orient ", chromolithographie, imagerie d'État, service de santé. W. Schutz, dessin politique dans Simplicissimus, Munich, 20 août 1916.

104. P. Squarzoni, Garduno, en temps de paix, Bordeaux, Les Requins-Marteaux, 2002.

105. Voir par exemple Notre Rire, $2^{\mathrm{e}}$ année, $n^{\circ}$ 9, juillet 1916. Image publiée dans La Presse 2017.

106. Rob-Vel, «Les aventures de Toto et de son pompon magique », bandeau titre, en couverture de Le Journal de Toto, $3^{\mathrm{e}}$ année, $\mathrm{n}^{\circ}$ 139, 2 novembre 1939.

107. Le Journal de bébé, $1^{\mathrm{er}}$ novembre 1932.

108. W. Busch, Max und Moritz, 1865, dans la traduction de Cavanna.

109. B. Rabier, Le Coq, coll. L'Esprit des bêtes, s.l.n.d.

110. Charlier et Uderzo, "Belloy, chevalier sans armure. Le baron maudit ", Pilote, $5^{\mathrm{e}}$ année, $\mathrm{n}$ - 197, $1^{\mathrm{er}}$ août 1963. Idem, sur un mode parodique : Pilote, 13e année, nº 587, 4 février 1971.

111. J. L. Munuera et J. Sfar, Merlin, 3, Merlin va à la plage, Paris, Dargaud, 2003.

112. Lob, Gotlib et Alexis, Super-Dupont, Paris, Album Fluide-Glacial, 1972, couverture mise en couleurs par Moebius ; couverture de Fluide Glacial Spécial SuperDupont, Paris, 1982. Mais Gotlib se moque de la poule dans «La poule », Rubrique-à-brac, t. 2, Neuilly-sur-Seine, Dargaud, 1971, 28-31.

113. Terme employé dans B. Rabier, Jeannot-Lapin et Cie, Paris, Tallandier, 1913, 22.

114. T. Gillian, « Buster, Have you ever stomped a Nigra? », Help!, Help Publishing Company, 1965, parodie d'un fascicule du Ku Klux Klan.

115. Omry (Georges Mory, 1880-1914), «La légende de la nuit », v. 1910. Angoulême, Cité de la bande dessinée et de l'image, inv. 95.1.51 et 52 .

116. F. Kupka, «Coq étranger et poules parisiennes », Le Rire, 31 octobre 1903 (Édouard VII à Paris).

117. Le projet de cette BD de propagande, dessinée dans les années 1950 par Norman Pett et Donald Freeman, est conservé aux Archives du Foreign Office (FO 1110/319), Kew, The National Archives. Autre adaptation en BD de La Ferme des animaux, sur un scénario de Jean Giraud et des dessins de Marc Bati : Bruxelles, Novedi, 1985. 
118. Par exemple dans l'île Maurice, en créole, sous le titre de Repiblik Zanimo, entre novembre 1974 et début avril 1975 dans le quotidien mauricien Libération, organe du parti UDM.

119. Silver (Guido Silvestri), Albert le loup, Grenoble, Glénat, [1979] 1986 ; Lupo Alberto est d'abord paru dans Undercomics, puis dans le Corriere dei Ragazzi, enfin dans Eureka; Sokal, Canardo, Premières enquêtes, Bruxelles, Pepperland, 1979 ; J.-G. Imbar et J.-L. Hubert, Le Polar de Renard, La Nuit des Ravageons, Neuilly-sur-Seine, Dargaud, 1982 ; Lax et M. Aubrun, Maxime Tourbillon, Du sang sur les groseilles, Grenoble, Glénat, 1984 ; G. Larson, The Chickens are restless, Kansas City, Andrews McMeel Publishing, [1993] 1999...

120. B. Galic et M. Lizano, Le Cheval d'orgueil, Toulon, Soleil, 2015.

121. F. Neidhardt, Les Pieds-Noirs à la mer, Vanves, Marabout, 2013.

122. Bisi, couverture de Corriere dei Piccoli, $X^{\mathrm{e}}$ année, $\mathrm{n}^{\circ} 24,16$ juin 1918.

123. G. Alanguilan, Elmer, Paris, Éditions Ça et là, (en ligne, 2006-2008) 2010. Les internautes avaient déjà plébiscité une série du même auteur : Stupid Chicken Stories.

124. Oncle Jack, "Les vacances de Tilutin », illustration de Norwins, L'Illustré à cinq centimes pour la jeunesse et la famille, $\mathrm{n}^{\circ}$ 65, 23 août 1905 (plagiat de la série américaine Buster Brown); J. Jeannet, "Bolo et sa tante ", Le Journal de bébé, $\mathrm{n}^{\circ} 100,1^{\mathrm{er}}$ septembre 1933 ; couverture de Fripounet et Marisette-Belles histoires de vaillance, 19e année, $\mathrm{n}^{\circ} 14,5$ avril 1959.

125. G. Bruno, Le Tour de la France par deux enfants. "Devoir et Patrie », 1877. On y voit aussi le coq et la poule de Bresse (657), race qui est « une des meilleures pour l'engraissement », et les oies de Lorraine (596).

126. Couderc 2005, 107-108.

127. « Scène d'enfant à peindre ", Le Journal de Bébé, $1^{\mathrm{er}}$ février 1933.

128. Ally Sloper's Half Holiday, vol. II, $n^{\circ}$ 57, 30 mai 1885.

129. L'Intrépide, $15^{\mathrm{e}}$ année, $\mathrm{n}^{\circ} 740,26$ octobre 1924.

130. Jeu, dessin de Cicerone, « Jouez avec Pilou », Tintin, n 309, 7 août 1981.

131. L. Knicksley, Délices. Ma vie en cuisine, Paris, Delcourt, 2014.

132. Mat, « Oscar le petit canard », Fillette, nouvelle série, $n^{\circ} 3,1^{\mathrm{er}}$ juin 1946.

133. Cartoon commandé pour la promotion des produits du terroir par la région Poitou-Charente et publié dans L'Actualité Poitou-Charente, 2007. Image très proche de l'illustration de couverture de Rustica. Journal universel de la campagne, 8 année, $\mathrm{n}^{\circ}$ 17, 28 avril 1935.

134. J.-Y. Ferri, Aimé Lacapelle, t. 3, Poules rebelles, Paris, Audie-Fluide glacial, 2003.

135. Shinji Saijo, Iron Wok Jan! R, 2, Paris-Toulon, Soleil Production, 2009.

136. Mars, «La poule qui a couvé un œuf d'autruche », Boum, $1^{\text {re }}$ année, $n^{\circ} 11,26$ août 1937.

137. W. Disney, «Quand les glands ont des ailes », Le Journal de Mickey, nouvelle série, n 609, 26 janvier 1964.

138. E. Froment, «Scènes familières ", gravé par Matthis, Magasin d'Éducation et de Récréation, $6^{\mathrm{e}}$ année, $n^{\circ} 133$, Paris, Hetzel, 20 septembre 1869 ; Bertrand, "Scènes de la vie rurale. Dans l'étable ", couverture de Le Petit Français illustré. Journal des écoliers et des écolières, $12^{\mathrm{e}}$ année, $\mathrm{n}^{\circ} 39$, 25 août 1900 ; ibid., 30 juin 1900.

139. Le Petit journal illustré de la jeunesse, $2^{\mathrm{e}}$ année, $\mathrm{n}^{\circ}$ 56, 5 novembre 1905.

140. Un blessé de la Grande guerre se remet de ses blessures, à l'hôpital, en lisant un livre d'histoire de France où est mis à l'honneur l'octroi de la poule au pot aux Français par Henri IV. Les Belles images, $12^{\mathrm{e}}$ année, $\mathrm{n}^{\circ}$ 569, 22 juillet 1915.

141. J. L. Devaux, «La ferme modèle », Pilote, $4^{\mathrm{e}}$ année, $\mathrm{n}^{\circ} 149,30$ août 1962 ; « La ferme », Spirou, $34^{\mathrm{e}}$ année, $\mathrm{n}^{\circ} 1716,4$ mars 1971.

142. H. Avelot, « Nouveaux tableaux d'école. Leçons de choses ». In Henri Avelot, «Les Maîtres humoristes ", $n^{\circ} 17$, Paris, Société d'Édition et de Publications, 1908.

143. Thomen, «Zoologie humoristique », American illustré, $1^{\text {re }}$ année, $n^{\circ} 4,20$ juillet 1907.

144. F. Neher, « Life's like that », Famous Funnies, $n^{\circ} 43$, février 1938.

145. « Le roi des coquilles d'œufs », Les Belles images, $16^{\mathrm{e}}$ année, $\mathrm{n}^{\circ} 780,7$ août 1919. 
146. Le Figaro illustré, juillet-août 1933, pointe une production insuffisante pour satisfaire la demande en œufs et poulets.

147. Rubrique "Échos du monde entier », «Les couveurs d'œufs à Manille », L'Intrépide, n 724, 6 juillet 1924.

148. J.-P. Pinchon, «Primerose et Rosalie ", en couverture de Fillette, $33^{\mathrm{e}}$ année, $\mathrm{n}^{\circ} 1745,28$ décembre 1941.

149. Bisi, «Sor Pampurio », Corriere dei Piccoli, XXXVe année, $n^{\circ} 8,21$ février 1943 ; « L'ottimista e il pessimista. La pollicoltura », Corriere dei Piccoli, $\mathrm{n}^{\circ} 12,1945$.

150. H. Le Monnier, Les Inventions du professeur Azimut, s.éd., s.l.s.d. [1943].

151. A. Saint-Ogan, « Potage. Encore la question des emballages », Ric et Rac, 15 janvier 1943.

152. L'Intrépide, $15^{\mathrm{e}}$ année, $\mathrm{n}^{\circ} 719,1^{\mathrm{er}}$ juin 1924.

153. Mat, «Oscar le petit canard », Fillette, nouvelle série, $n^{\circ} 3,1^{\mathrm{er}}$ juin 1946.

154. J. Hatlo, «A Visit to the Farm », 20 octobre 1946.

155. King, « Gasoline Alley », Sunday News, 23 novembre 1947.

156. «Walt Disney presents Donald Duck », 1951 (?).

157. Mat, « Le professeur Bigoudi », Wrill, $3^{\mathrm{e}}$ année, $\mathrm{n}^{\circ}$ 106, 10 juillet 1947.

158. P. Lacroix et R. Lortac, «Bibi Fricotin en l'an 3000 », Le Journal de Bibi Fricotin, 1957, rééd. 2017.

159. L. Falk et P. Davis, « Mandrake le Magicien », Le Journal de Mickey, $n^{\circ} 1008,10$ octobre 1971.

160. Voir dans ce même volume l'article de Frédéric Graber.

161. H. Gray, Little Orphan Annie, New York, Cupples \& Leon Company, 1926.

162. «Bicot, Ursule et Cie », traduction-adaptation française de M. Branner, « Winnie Winkle ", Coq hardi, nouvelle série, $\mathrm{n}^{\circ}$ 122, 26 mars 1953.

163. Rubrique « Échos du monde entier », L’Intrépide, $\mathrm{n}^{\circ} 729,10$ août 1924.

164. Rubrique «Échos du monde entier », L'Intrépide, n 747, 14 décembre 1924.

165. «Le plus grand poulailler du monde », article illustré, Hardi !, $1^{\text {re }}$ année, $n^{\circ} 19,31$ octobre 1937.

166. «De plus en plus de poulets ", rubrique «Les nouvelles », Spirou, $21^{\mathrm{e}}$ année, $\mathrm{n}^{\circ} 1069,9$ octobre 1958.

167. « Le coq, la poule, les poussins », Schtroumpf, n 7, mai 1990.

168. Pica et Bouchard, "Les poules à lier », Spirou, 58 a année, $n^{\circ}$ 3007, 29 novembre 1995.

169. «Clever boys these kids », The Katzenjammer Kids, Feature book, n 37, 1943.

170. L. Falk et P. Davis, « Mandrake le Magicien », Le Journal de Mickey, $n^{\circ} 1008,10$ octobre 1971.

171. Balk, « Punky », Famous Funnies, n 43, février 1938.

172. Meb, « Animals in the news », Famous Funnies, n 43, février 1938.

173. Hake's Americana, publicité dans Inside Collector $1993,2^{\mathrm{e}}$ intérieure.

174. «Des poules sans ailes", rubrique "C'est curieux mais vrai ", Bravo, $9^{\mathrm{e}}$ année, $n^{\circ} 38,22$ septembre 1949.

175. Par exemple "Little Red Riding Hood», publicité pour les burgers «Jack in the Box », Los Angeles Herald Examiner, $1^{\mathrm{er}}$ décembre 1968.

176. "The Day after Doomsday », Weird War Tales, vol. 4, n 32, décembre 1974.

177. J. Danon et Y. Got, «La longue empoignade de l'homme et de la terre nourricière ou L'histoire de l'agriculture ", Pilote, $13^{\mathrm{e}}$ année, n 615, 19 août 1971.

178. Hulet et Blareau, «Charabia », Nouveau Tintin, $n^{\circ} 131,14$ mars 1978.

179. Bara, « Max l'explorateur », Tintin, $27^{\mathrm{e}}$ année, $n^{\circ} 24,13$ juin 1972.

180. Bob, «Adonowai », Tintin, $n^{\circ} 281,1978$.

181. G. Larson, The Far Side, 14, The Chicken are Restless, Kansas City, Andrews McMill Publishing, [1993] 1999 ; G. Alanguilan, Elmer, Paris, Éditions Ça et là, 2010.

182. Ibn Al Rabin, Cot Cot, Genève, Atrabile, 2003. 
183. J. et B. Mirroir, ou Pluttark, «La terrible vérité sur le poulet frit » [du Kentucky, PFK, allusion au KFC], Fluide glacial, série Or, Nouvelle Gastronomie, De la verrine à la louche, septembre 2013.

184. Borgne, dessin humoristique, in Ibid.; "S comme Superpoulet», Kaboom, 2016, voir www.comixology.fr

185. J.-Y. Ferri, Aimé Lacapelle, t. 3, Poules rebelles, Paris, Fluide glacial, 2003 ; G. Alanguilan, Elmer , Paris, Éditions Ça et là, 2010.

186. P. Garand, Le Petit ๔Euf, t. 3, Bande de chicken nuggets!, Valenton, Poulailler Production, 2007.

187. J. Layman et R. Guillory, Tony Chu, détective cannibale, t. 1, Goût décès, Paris, Delcourt, 2010.

188. « Au rien à branler ", dessin humoristique, Fluide glacial, série Or, Nouvelle Gastronomie, De la verrine à la louche, septembre 2013.

189. J.-Y. Ferri, Aimé Lacapelle, t. 3, Poules rebelles, Paris, Fluide glacial, 2003.

190. Carali, La Poule à Paulot, Plessis-Saint-Jean, Zébu Éditions/Psykopat, 2002.

191. G. Baxter, "Suggestion: A Rietveld egg and anchory salad», Glen Baxter's Gourmet Guide, Londres, Bloomsbury, 1997.

192. Nob, La Cuisine de Mamette, Grenoble, Glénat, 2013, recette des œufs cocotte.

193. P. Simmonds, Tamara Drewe, trad. fr. Paris, Denoël, 2008.

194. Carali, La Poule à Paulot, Plessis-Saint-Jean, Zébu Éditions, Psykopat, 2002.

195. Sous la plume de P. Garrand, Valenton, Poulailler Production.

\section{RÉSUMÉS}

Animal abondamment figuré dans la bande dessinée (environ 1500 histoires dont $30 \%$ ont des gallinacés pour héros), icône de la ruralité, la poule est très souvent anthropomorphisée. Tantôt elle incarne des valeurs maternelles (protectrice et avisée), tantôt elle est présentée comme stupide et devient source de gags. L'image du coq, mais aussi de la poule, est politisée dès l'orée du XXe siècle. Si le coq est du côté des conquérants, le poulet et la poule sont surtout du côté des opprimés. À travers l'élevage avicole, la bande dessinée se fait l'écho des pratiques sociales et économiques de son temps. Depuis la fin des années 1970, aux États-Unis, et la fin des années 2000, en France, le thème est l'occasion de dénoncer l'industrialisation de l'alimentation, les fastfoods et la « malbouffe».

Much present in comics (some 1500 strips of which $30 \%$ have a gallinaceous hero), rural icon, the hen is very often anthropomorphised.

Sometimes it stands for maternal values (protective and wise), sometimes it is depicted as stupid and constitutes a source of jokes. The rooster's image, and that of the hen also, is used as a political metaphor as soon as the beginning of the XXth century. If the rooster is on the conquerors side, chickens and hens are in the oppressed camp. When dealing with poultry breeding, comics books are reflecting social and economics issues of their times. Since the end of the 1970's in the US and the end of the 2000's in France the theme is an opportunity to denounce industrial food, fast food and junk food. 
INDEX

Keywords : representation, rurality, humor, politic, economy, poultry breeding, alimentation Mots-clés : représentation, ruralité, humour, politique, économie, élevage, alimentation

\section{AUTEUR}

DANIĖLE ALEXANDRE-BIDON

GAM, CRH/CNRS

alexandr@ehess.fr 